\title{
Formation of nickel-iron meteorites by chemical fluid transport
}

\author{
Werner Schrön* \\ Kernbergstraße 52a, 07749 Jena, Germany \\ *Corresponding author's e-mail address: weschroen@gmx.de
}

Published online: 20 October 2016 (version 1); 18 October 2017 (version 2); 25 February 2019 (version 3)

Cite as: W. Schrön. ScienceOpen Research 2019 (DOI: 10.14293/S2199-1006.1.SOR-EARTH.A2TIA5.v3)

Reviewing status: Please note that this article is under continuous review. For the current reviewing status and the latest referee's comments, please click here or scan the QR code at the end of this article.

Primary Discipline: General earth science

Secondary Discipline: General geosciences, Geology \& Mineralogy, General chemistry

Keywords: Iron Meteorites, Solid-gas Equilibrium Reactions, Reaction-conditioned Pressure, Siderophile Elements, Metal-silicate Separation, Ataxites, Hexahedrites, Octahedrites, Lawrencite, Kamacite, Taenite, Troilite, Schreibersite, Cohenite, Widmanstätten Patterns, Germanium-gallium Correlation, Heterogeneous Accretion

\section{ABSTRACT}

The deposition of solid material from the gas phase via chemical vapor transport (CVT) is a well-known process of industrial and geochemical relevance. There is strong evidence that this type of thermodynamically driven chemical transport reaction plays a significant role in certain natural processes. This article presents detailed evidence that CVT is a highly plausible mechanism for the formation of iron meteorites. In this study, naturally occurring CVT is referred to as "chemical fluid transport" (CFT) and the end products deposited from the gas phase as "fluidites."

Treating iron meteorites as cosmic fluidites enables simple solutions to be found to the problem of how they formed and to numerous related and in some cases unresolved questions.

This study is based on a thermodynamic trend analysis of solid-gas equilibrium reactions involving chlorine- and fluorinecontaining compounds of 42 chemical elements that include a systematic examination of reaction dominance switching behavior. In order to assess the transport behavior of the individual elements, the reaction-conditioned pressures $\mathrm{p}_{\mathrm{MeX}}$ were calculated from the equilibrium constants. For a selected group of minerals, the relative propensity of these minerals to deposit from the gas phase was then derived from the equilibrium constants. The study shows that octahedrites, hexahedrites and ataxites formed as a result of the transport of metal chlorides and fluorides (CFT) during accretion within the solar nebula. Siderophile elements are characterized by the similarities in their chemical transport properties. These chemical properties of the elements, expressed in the form of the reaction-conditioned pressure, play a key role in determining the chemical composition of iron meteorites. The mobilization process that leads to the formation of the gaseous metal halides MeX includes the reduction of oxides. The deposition of nickel-iron bodies occurs via back reaction after the transport of the gaseous halides. The back reaction leads to the thermodynamically favored deposition of schreibersite before troilite and of troilite before kamacite/taenite. The deposition temperature of octahedrites and hexahedrites lies below the temperature at which Widmanstätten patterns would be destroyed, while that of ataxites lies slightly above. Similarly, the occurrence of thermally instable cohenite in meteorites provides further support for the fluidite character of irons.

The variation in the trace element concentrations in iron meteorites is explained by enrichment and depletion mechanisms in the gas phase. The striking correlation between gallium and germanium abundances in iron meteorites is the result of similarities regarding the mobilization phase and the reaction dominance switching behavior of both elements, and crystal isomorphism.

These findings are supported by numerous arguments that provide evidence for the CFT model. The occurrence of the mineral lawrencite $\mathrm{FeCl}_{2}$ in meteorites is interpreted as an indication of the effectiveness of the chemical transport of $\mathrm{FeCl}_{2}$. The presence of meteorite alteration and the observed deviations from the solar elemental abundances in silicate meteorites are also explained in terms of the effectiveness of CFT-based mobilization.

\section{INTRODUCTION}

Our planetary system is not just the product of physical processes chemical processes have also played a crucial role in its formation.

In the early stages of the creation of the solar system, condensation processes within a cooling gas of cosmic composition played a crucial role (Anders, 1969; Blander \& Abdel-Gawad, 1969; Grossman, 1972; Larimer, 1967; Wai \& Wasson, 1977 in 
Schrön, 1990). The condensation model presented by Davis and Richter (2014) posits that most of the Fe-Ni metal condenses after the formation of refractory calcium-aluminum-rich inclusions in chondrites (CAIs).

According to current opinion, iron meteorites and some stonyiron meteorites are fragments of asteroids. These asteroidsthe parent bodies of the meteorites-underwent a process of geological evolution during a very early phase of the solar system that included the melting of metals and silicates, and differentiation to create asteroids with a core-mantle structure (Chabot \& Haack, 2006; Goldstein, Scott, \& Chabot, 2009; McCoy, Mittlefehldt, \& Wilson, 2006 in Benedix, Haack, \& McCoy, 2014; Krot, Keil, Scott, Goodrich, \& Weisberg, 2008; Weisberg, McCoy, \& Krot, 2006 in Goldstein et al., 2009). After cooling extremely slowly, these parent asteroids are assumed to have been broken up by impacts occurring in the asteroid belt (Goldstein et al., 2009), resulting in the release of iron meteorites. The observed variation in the chemical composition and crystallization conditions in iron meteorites is explained by assuming that they stem from a large number of parent asteroids, currently estimated at more than 60 . All of the data and characteristics relating to these iron meteorites (analysis results, structural features, cooling rates) have been successfully assigned to these parent bodies.

The Widmanstätten patterns observed in some iron meteorites can be explained on the basis of the $\mathrm{Fe}-\mathrm{Ni}$ phase diagram. When the molten material cools, initially only the taenite phase is present. On further cooling, the system enters a binary phase region in which the mineral kamacite also forms. As the material continues to cool at an extremely slow rate, the kamacite is believed to grow as two-dimensional lamellae into the surrounding taenite at the expense of the taenite resulting in the formation of what are known as Widmanstätten patterns (Goldstein et al., 2009). The metallographic cooling rates are derived from the kamacite growth models and have been shown in the case of the Of Duchesne meteorite to be $200 \mathrm{~K} /$ Myr with cooling times of 10 Myr (Goldstein et al., 2009).

However, this explanation leads to problems with the time available for cooling, and furthermore, it cannot be tested experimentally. It is particularly problematic that Widmanstätten patterns are predicted to form during cooling within a certain temperature range, as it has been demonstrated that heating an octahedrite to this same temperature range causes the irreversible destruction of the Widmanstätten patterns. The destruction of Widmanstätten patterns by heating was demonstrated experimentally on octahedrites when material from the Og Toluca meteorite was heated to $950^{\circ} \mathrm{C}$ (approx. 1220 K) (Heide, 1957; Heide et al., 1995). Another observation that supports the chemical fluid transport (CFT) model and refutes the idea that these iron meteorites were formed as a result of extremely slow cooling of the melt is the presence of cohenite in octahedrites, as cohenite could not have survived at such temperatures and would have undergone thermal decomposition (Argument 11).
An additional difficulty with the currently accepted model is that it cannot yield hexahedrites. Existing hexahedrites consist almost entirely of kamacite. According to the Fe-Ni phase diagram, the cooling melt always first forms taenite (minimum Ni content: $30 \%$ ), and the complete transformation from taenite to kamacite (Ni content: 4-7.5\%) would seem to be very difficult to achieve. Goldstein et al. (2009) report problems when comparing the cooling rates determined by different models. A number of different approaches have been suggested all of which aim to circumvent the "time problems" caused by the extremely slow cooling rates (e.g. Bottke, Nesvorný, Grimm, Morbidelli, \& O’Brien, 2006; Yang, Goldstein, \& Scott, 2007). Papers published by Goldstein et al. (2009), Benedix et al. (2014); and others do not provide a convincing explanation of the observed distributions of trace elements, such as the variation in the abundances of germanium found in iron meteorites.

Some of the formation models described above, including the role of impact events, are applicable to the creation of stonyiron meteorites, although in this case there is no need to postulate extremely low cooling rates.

In contrast, the formation of iron meteorites in the CFT model discussed here does not involve any melt processes or extremely slow cooling, and there is no requirement for impact events and no time problem. Numerous iron meteorites are single crystals-a fact that is more simply explained using CFT. CFT also provides explanations for the reduction of oxide components, the phenomenon of siderophile elements and the observed variation in the germanium content in iron meteorites.

\section{CHEMICAL TRANSPORT PROCESSES AND SOLID-GAS EQUILIBRIUM REACTIONS}

Chemical transport processes occur spontaneously in nature. In the laboratory, this type of reaction is typically referred to as a chemical vapor transport reaction (CVT or CVTR) and is used, for example, for growing crystals and in other preparative techniques in solid-state chemistry (Binnewies, Glaum, Schmidt, \& Schmidt, 2011; Schäfer, 1962). A key aspect of CVT is mass transport in the gas phase. Generally, CVT involves reacting a non-volatile solid substance with a gas such as $\mathrm{HX}$ $(\mathrm{X}=\mathrm{Cl}, \mathrm{F})$ to form a volatile compound that undergoes gasphase mass transport from the source to another location where the back reaction is thermodynamically favored, thus re-depositing the original solid substance. The chemical transport reaction phenomenon was first observed in nature (Binnewies et al., 2011). These naturally occurring chemical transport reactions are referred to here as CFT processes and the end products are referred to here as "fluidites" (Schrön, 2013 refers to them as "fluidic minerals"). The term "fluidites" refers to all minerals and rocks that have been formed as a result of a CFT reaction, even when the gas-phase transport stage is followed by hydrothermal transport. The chemical composition of the fluidites found in the Earth's crust (major and trace elements) is determined predominantly by the 
reaction/volatilization phase (referred to here as the "mobilization phase") and to a lesser degree by the subsequent gasphase transport and deposition processes. A discussion of the principles underlying the mobilization and transport processes in CFT is presented in Schrön (2013).

For the purposes of this article, it is important to appreciate a key difference between CVT and CFT. In CVT, laboratory conditions (purity of the reactant, choice of transport gas, temperature, temperature gradient) are frequently selected so that a highly pure end product results. In the case of CFT, however, both major components and trace elements are transported, and the presence of these trace elements, which is a reflection of their similar chemical properties, provides an indication-in many cases the only indication-that CFT has occurred. Identifying and recognizing the role played by fluidites is still in its infancy. Large quantities of fluidites can be formed when CFT occurs in combination with the cyclical processes that take place within the Earth's crust or when the product (fluidite) is removed from the initial site of deposition either as a result of transport mechanisms within the crust or via transport into the sea (Schrön, 1989a, 2013). Cyclical processes arise when the gas involved in the CFT process (typically $\mathrm{HCl}$ or hydrogen fluoride (HF)) is released when deposition (via the back reaction) and is made available again to participate in the CFT process. The formation of pneumatolytic minerals and metasomatic rocks and that of a number of significant ore deposits can be better explained by invoking the concept of CFT in combination with cyclical processes (see Schrön, 2013).

The systematic studies that underpin these ideas (Schrön, 1989a, 1989b, 1990, 1994, 2013; Schrön, Oppermann, Rösler, $\&$ Brand, 1988) have demonstrated that siderophile elements exhibit the same CFT behavior and that they can be transported as the gas-phase metal halide by the CFT mechanism. This approach allows a CFT-based model for the formation of iron meteorites to be developed. While the idea that iron meteorites are fluidites deposited directly from the gas phase may appear incredible at first, further examination shows that this approach deserves serious consideration.

The CFT process can be described in terms of the thermodynamics of solid-gas equilibrium reactions: "Die chemischthermodynamische Analyse von Fest-Gas-Gleichgewichten einfacher und komplex zusammengesetzter Bodenkörper ermöglicht die Vorhersage des Transportverhaltens auch in mehrkomponentigen Systemen" ["The chemical thermodynamic analysis of solid-gas equilibria involving solids of both simple and complex composition enables the transport behavior of these materials to be predicted even in multicomponent systems."] (Wolf et al., 1978, see also Schrön et al., 1988 and Schäfer, Jacob, \& Etzel, 1956). This type of thermodynamic analysis also enables trends such as the response of the reaction to changes in temperature and pressure to be studied. A simple thermodynamic trend analysis was carried out on the chlorides and fluorides (including the oxychlorides and oxyfluorides) of
42 chemical elements in the temperature range 500-2000 K and included the systematic identification of the dominant reaction when more than one equilibrium reaction is possible for a particular element. Particular attention was paid to determining whether a particular element is preferentially transported as a chloride or as a fluoride. The direction of transport is determined by the thermodynamics of the reaction between the solid and the transport gas. If the reaction is exothermic (negative $\Delta \mathrm{H}$ ), the solid will be transported to a hotter location. Conversely, if the reaction is endothermic (positive $\Delta \mathrm{H}$ ), the solid will be transported to a cooler location. In the case of reactions of mineral oxides (mostly silicates) with $\mathrm{HX}(\mathrm{X}=\mathrm{Cl}, \mathrm{F})$, the transport mechanism is based on the following solid-gas equilibrium reaction (1):

$$
\mathrm{Me}_{\mathrm{y}} \mathrm{O}_{\mathrm{z}}, s+2 z \mathrm{HX}, g \leftrightarrow y \mathrm{MeX}_{\frac{2 z}{y}}, g+z \mathrm{H}_{2} \mathrm{O}, g
$$

To analyze the CFT of elemental metals, the metal oxide $\mathrm{Me}_{\mathrm{y}} \mathrm{O}_{\mathrm{z}}$ in equilibrium reaction (1) has to be replaced by the metal $\mathrm{Me}$, yielding the solid-gas equilibrium reaction (2):

$$
y \mathrm{Me}, s+2 z \mathrm{HX}, g \leftrightarrow y \mathrm{MeX}_{\frac{2 z}{y}}, g+z H_{2}, g,
$$

where s represents solid and g represents gas. Both $\mathrm{HCl}$ and HF were present in small quantities in the solar nebula. The analysis also assumes that equilibrium is established, so that vapor-phase mass transport can in fact occur. Thermodynamic analysis enables the temperature-dependent equilibrium constants $\mathrm{K}_{\mathrm{p}}$ to be calculated from the temperature $\mathrm{T}$, the reaction enthalpy $\Delta \mathrm{H}_{\mathrm{r}}{ }^{0}$ and the reaction entropy $\Delta \mathrm{S}_{\mathrm{r}}{ }^{0}$ :

$$
\lg \mathrm{Kp}=\frac{T \cdot \Delta \mathrm{S}_{\mathrm{r}}^{0}-\Delta \mathrm{H}_{\mathrm{r}}^{0}}{4,575 \cdot \mathrm{T}}
$$

where the gas constant $\mathrm{R}$ is implicitly expressed in cal. $\mathrm{K}^{-1} \mathrm{~mol}^{-1}$.

The propensity of specific minerals to deposit directly from the gas phase was determined by analyzing the equilibrium constants of the relevant solid-gas equilibrium reactions (see Table 1).

Assessing the transport properties of the individual gas-phase metal halides is best done by means of the partial pressure $\mathrm{p}_{\mathrm{MeX}}$, which can be derived from the equilibrium constant for the corresponding solid-gas equilibrium reactions (1) or (2) and which is referred to here as the "reaction-conditioned pressure"-a term introduced in Schrön (1989a):

$$
\lg \mathrm{p}_{\mathrm{MeX}_{\frac{2 z}{y}}}=\frac{\Delta \mathrm{S}_{\mathrm{r}}^{0}}{y \cdot 4,575}-\frac{1}{\mathrm{~T}} \cdot \frac{\Delta \mathrm{H}_{r}^{0}}{y \cdot 4,575}+\frac{1}{y} \lg \frac{p_{H X}^{2 z} \cdot C^{y}}{p_{H_{2} O}^{z}}
$$

Equation (4) is derived from equilibrium reaction (1). 
Table 1. Equilibrium constants $K_{p}$ at different temperatures $(T)$ for equilibrium reactions involved in the CFT model of mineral formation (Schrön, 1989b, 2013). 6 = kamacite/taenite, $7=$ troilite, and $8=$ schreibersite.

\begin{tabular}{llll}
\hline $\mathrm{T}$ in $\mathrm{K}$ & $\mathrm{K}_{\mathrm{p}} \mathbf{6}$ & $\mathrm{K}_{\mathrm{p}} \mathbf{7}$ & $\mathrm{K}_{\mathrm{p}} \mathbf{8}$ \\
\hline 500 & $10^{-4}$ & $10^{-10}$ & $10^{-17}$ \\
1000 & $10^{-1}$ & $10^{-3}$ & $10^{-13}$ \\
2000 & $10^{0}$ & $10^{0.4}$ & $10^{-11}$ \\
\hline
\end{tabular}

$$
\lg \mathrm{p}_{\mathrm{MeX}_{\frac{2 z}{y}}}=\frac{\Delta \mathrm{S}_{\mathrm{r}}^{0}}{y \cdot 4,575}-\frac{1}{\mathrm{~T}} \cdot \frac{\Delta \mathrm{H}_{r}^{0}}{y \cdot 4,575}+\frac{1}{y} \lg \frac{p_{H \mathrm{X}}^{2 Z}}{p_{H_{2}}^{z}}
$$

Equation (5) is derived from equilibrium reaction (2).

$\mathrm{p}_{\mathrm{MeX}}, \mathrm{p}_{\mathrm{H} 2}$, and $\mathrm{p}_{\mathrm{HX}}$ are the partial pressures of the corresponding gaseous species MeX, $\mathrm{H}_{2}$ and $\mathrm{HX}$. The partial pressure $\mathrm{p}_{\mathrm{MeX}}$ indicates the extent to which a metal halide in the equilibrium reaction (1) or (2) undergoes mobilization and transport, and it is for this reason that $\mathrm{p}_{\mathrm{MeX}}$ has been referred to previously as the "reaction-conditioned pressure" (Schrön, 1989a,1989b). The reaction-conditioned pressure $\mathrm{p}_{\mathrm{Mex}}$ depends on the element involved, the temperature, and the composition of the gas phase. The temperature dependence of $\mathrm{p}_{\mathrm{MeX}}$ is shown in Figure 1 for the most important elements. The reaction-conditioned pressures $\mathrm{p}_{\mathrm{MeX}}$ are generated by a thermodynamic trend analysis and are in principle independent of any assumption regarding a transport limit. The dependence of the reaction-conditioned pressure or the dominance-change temperature on the total pressure $\mathrm{p}_{\text {tot }}$ is shown for selected metal chlorides in Figure 2. The temperature-dependent trends shown in Figures 1 and 2 are robust and reliable; however, the absolute values may not be accurate. Comprehensive dominance-change studies in systems of geochemical and cosmochemical significance have already been reported (Schrön, 1989a, 1989b; Schrön et al., 1988). All equilibrium constants $K_{p}$ were calculated on the basis of standard enthalpies $\Delta \mathrm{H}_{\mathrm{f}}{ }^{0}$ and entropies $\mathrm{S}^{0}$ (298 K; 1 bar) taken from specialist sources (Barin, Knacke, \& Kubaschewskij 1973/1977; Gluschko, 1971/1981; Gluschko \& Gurvic, 1978/ 1982; JANAF, 1971; Krabbes \& Oppermann, 1977; Naumov, Ryzenko, \& Chodakovski, 1971; Oppermann, Schmidt, \& Kleinert, 1983).

In addition to the reaction-conditioned pressure $\mathrm{p}_{\mathrm{MeX}}$, gas-phase transport of the metal halide requires a sufficiently high saturation vapor pressure $\mathrm{p}_{\text {MeX }}^{\mathrm{s}}$ (see Figure 1 in Schrön (2013) for saturation vapor pressures $\mathrm{p}^{\mathrm{s}}{ }_{\mathrm{MeX}}$ ).

Consider the equilibrium reaction (6), which is of relevance for the meteoritic minerals kamacite and taenite:

$$
\mathrm{Fe}, \mathrm{s}+2 \mathrm{HCl}, \mathrm{g} \leftrightarrow \mathrm{FeCl}_{2}, \mathrm{~g}+\mathrm{H}_{2}, \mathrm{~g}
$$

The temperature-dependent trend in the equilibrium constant $\mathrm{K}_{\mathrm{p}} 6$ is shown in Table 1 for three representative temperatures. As can be seen, at temperatures above about $2000 \mathrm{~K}$ the equilibrium will lie to the right, and gaseous iron(II) chloride

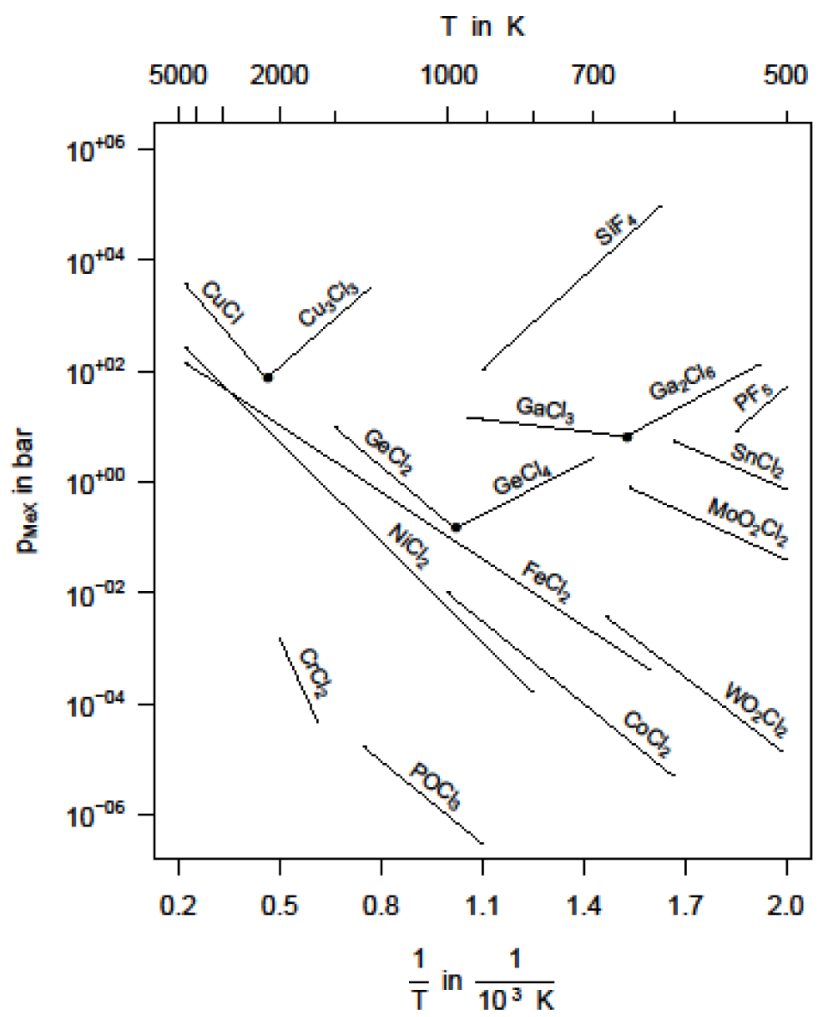

Figure 1. Diagram of reaction-conditioned pressure $\left(p_{M e X}\right)$ at different temperatures (1/T) for selected MeX compounds in accordance with equilibrium reaction (1) (Schrön et al., 1988, Figures 1 and 2). dominance changes $\mathrm{GeCl}_{2} / \mathrm{GeCl}_{4}, \mathrm{GaCl}_{3} /$ $\mathrm{Ga}_{2} \mathrm{Cl}_{6}$, and $\mathrm{CuCl} / \mathrm{Cu}_{3} \mathrm{Cl}_{3}$.

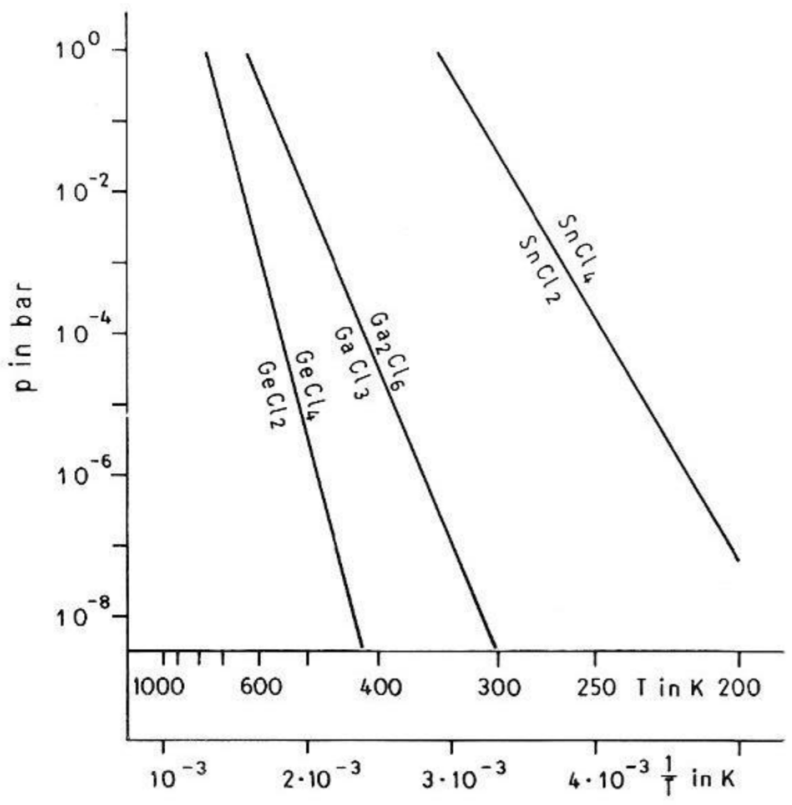

Figure 2. $\mathrm{GeCl}_{2} / \mathrm{GeCl}_{4}, \mathrm{GaCl}_{3} / \mathrm{Ga}_{2} \mathrm{Cl}_{6}$, and $\mathrm{SnCl}_{2} / \mathrm{SnCl}_{4}$ dominance changes depending on temperature and total pressure $p_{\text {tot }}$ in accordance with equilibrium reaction (2). 
is formed. At temperatures below $2000 \mathrm{~K}$, the equilibrium lies to the left, and the back reaction is favored, leading to re-deposition of metallic iron solely as a response of the equilibrium to lower temperature. The position of the equilibrium in equilibrium reaction (6) will also shift to the left in response to the partial pressure $\mathrm{p}_{\mathrm{H} 2}$ of the hydrogen present in the solar nebula. Equilibrium reaction (6)-or the more general case (2)-is significant both in terms of the mobilization (forward reaction) and the re-deposition of the metal (back reaction). Equilibrium reactions involving the metal oxide (1) are of significance only in terms of the mobilization phase and in the role they play in reducing the oxide.

Quite why so few authors have attempted to use thermodynamic analyses of solid-gas equilibria reactions to solve questions of geochemical and cosmochemical interest is hard to understand. Despite the fact that naturally occurring chemical transport reactions were first recorded in the mid-19th century, ${ }^{1}$ little attention is paid to them today. This is all the more surprising given the fact that thermodynamic analyses of solid-gas equilibria reactions in combination with naturally occurring cyclical processes provide an explanation of largescale gas-phase mineral transport that is of direct significance in the geosciences.

\section{ARGUMENTS FOR THE FORMATION OF NICKEL-IRON METEORITES BY CFT}

All of the arguments presented in this study concern nickeliron meteorites belonging to the structural classes octahedrites, hexahedrites, and ataxites. They were found on Earth and originated within the asteroid belt. These meteorites are considered to represent examples of matter that has been unchanged in terms of its material and structural properties since the creation of the solar system. The matter of which they are composed is believed to have formed through a process of accretion during the creation of the early solar system (Corrigan \& Libourel, 2014; Kleine \& Rudge, 2011). It is argued here that CFT may have played a significant role in this process. The focus is on octahedrites whose Widmanstätten patterns are irreversibly destroyed at high temperatures. Widmanstätten patterns are essentially a guarantee that sample material has remained unchanged since its formation. The octahedrites are therefore particularly attractive for the types of arguments being presented here. However, it may also be assumed that the hexahedrites and ataxites are also representative of material that was present in the early solar system. As Amelin and Ireland (2013) state: "The early history of our Solar System cannot be observed directly. It is recorded in the early minerals and rocks that were removed from the final stages of accretion before formation of the planets. These primitive rocks are preserved in asteroids that experienced only moderate heating

1. Both Breithaupt (1849) and Bunsen (1852) described the transport of iron in the form of gaseous iron chloride as a naturally occurring process on volcanoes (Binnewies et al., 2011; Schrön 1990, 2013) and in comets. Other asteroids that were extensively melted are thought to be the sources of igneous meteorites." Moderate heating does not destroy the Widmanstätten patterns in octahedrites. Octahedrites (as well as hexahedrites and ataxites) can therefore be considered to be fluidites that are classified either within the group of "primitive rocks preserved in asteroids" or, perhaps more appropriately, as a separate group. Either way, the "primitive rocks" and fluidites did not undergo extensive melting, in contrast to the stony-iron ("igneous") meteorites.

Irons meteorites and stony-iron meteorites can also be distinguished by the fact that irons (octahedrites, hexahedrites and ataxites) are almost always found to contain no silicates. As Urey (1952) writes: "[...] the stones usually contain some amount of metal phase though the irons have no silicate phase, except that a small group of the ataxites contain up to 5 per cent by weight of forsterite [...]." This observation by Urey highlights a key difference between iron meteorites and the metal phases in stony-iron meteorites.

In the absence of any new compilations of analytical data relating to the chemical composition of iron meteorites, a selection of suitable meteorites was chosen for this study. Table 2 presents the major and trace elements found in iron meteorites. In presenting these data, we have sought to include meteorites in which the concentration of a specific element is typical for a particular class and those in which the concentration represents an extreme value. The elements shown in Table 2 were also selected based on the gas-phase transport properties of the corresponding halides. By including iron meteorites that exhibit extreme element concentrations, Table 2 also contains examples of anomalous ataxites, various polycrystalline and abnormal iron meteorites.

In the CFT model of metal-silicate separation in the solar nebula discussed here, gaseous metal chlorides are formed through two possible channels. One channel is equilibrium reaction (1) (see page 3 ) in which $\mathrm{HCl}$ reacts with elements contained within the small silicate particles present in the solar nebula (e.g. carbonaceous chondrites; H, L, LL chondrites and achondrites) during accretion.

The other channel involves equilibrium reaction (2) (see page 3) in which $\mathrm{HCl}$ reacts with small metallic particles (e.g. nickel-iron from chondrites or, possibly, nickel-iron that has condensed during accretion).

The gaseous metal chlorides are then transported in accordance with the thermodynamics of the forward and back reactions. If the forward reaction between the metal and $\mathrm{HCl}$ is endothermic, the corresponding back reaction will be exothermic and the solid metal will be re-deposited at a cooler location. This mechanism results in the direct deposition of nickel-iron bodies from the gas phase. The siderophile elements are transported as metal halides and are present as major and trace elements in the nickel-iron matrix.

As the back reaction in equilibrium reaction (2) releases the transport agent $\mathrm{HCl}$, which then becomes available again to 


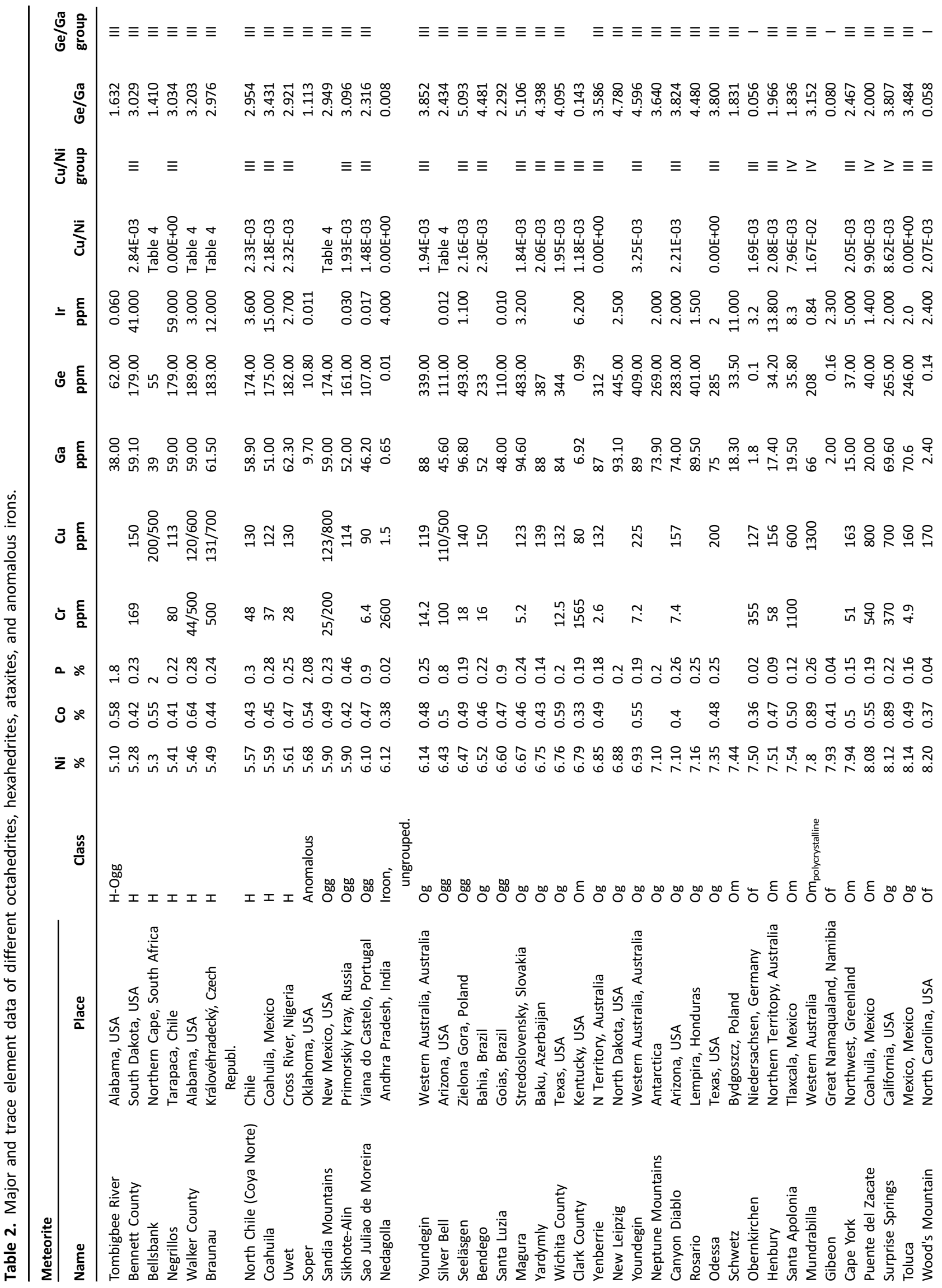




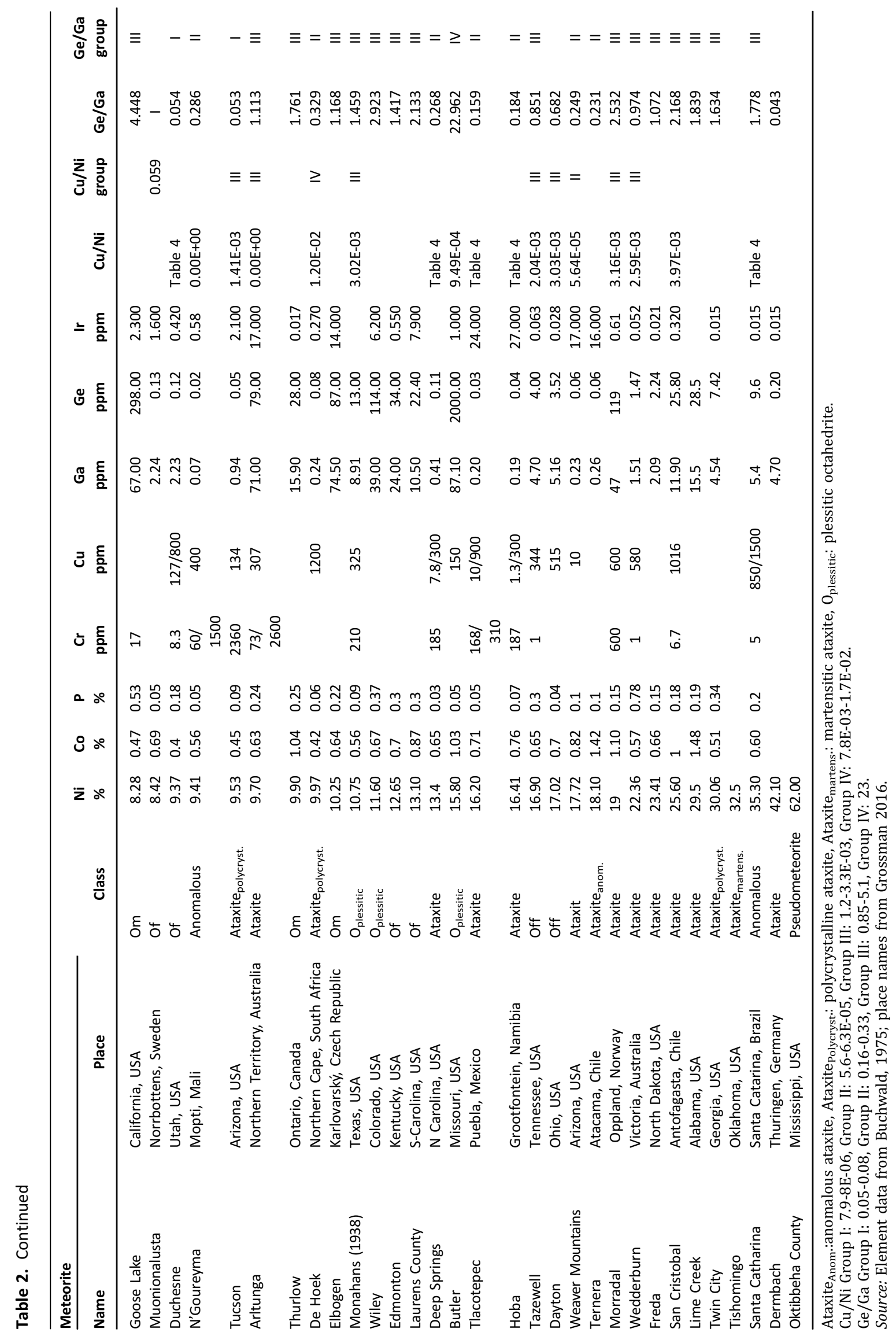


drive the forward reaction, this cyclic process can result in the deposition of significant quantities of metal. In addition to $\mathrm{HCl}$, HF may also function as the transport agent, so that for some elements the volatile metal fluoride may be the species undergoing gas-phase transport. The thermodynamic calculations used in the CFT model do not allow exact computation of an upper temperature limit for the transport process. The lower temperature limit is assumed to be around $600 \mathrm{~K}$ based on saturation vapor pressure data for the halides of siderophile elements. At temperatures below about $600 \mathrm{~K}$, the chlorides of the major elements $\mathrm{Fe}, \mathrm{Ni}$, and $\mathrm{Co}$ begin to condense out of the gas phase (See Figure 1 in Schrön, 2013). The CFT model of the formation of iron meteorites and the conclusions drawn from it are supported by the arguments presented in the following sections.

\section{Argument 1: CFT under cosmochemical conditions}

CFT can occur even under extreme conditions. In fact, in certain cases, the cosmochemical conditions within the solar nebula favor CFT. The hydrogen halides required for the equilibrium reactions (1) and (2) are present in small quantities in the solar nebula. The solar-system elemental abundance of fluorine is 843 per million silicon atoms, while that of chlorine is 5240 per million silicon atoms (Anders \& Grevesse, 1989). The distribution of $\mathrm{HCl}$ and the discovery of $\mathrm{HF}$ in the interstellar dust have been described by Neufeld, Zmuidzinas, Schilke, and Phillips (1997). Goles, Greenland, and Jerome (1967) reported on the abundances of other halogens in meteorites.

The equilibrium reactions (1) and (2) are able to describe the mobilization and transport of gaseous metal halides under cosmochemical conditions. Given the time available in cosmochemical processes, it seems reasonable to assume that chemical equilibrium is established between the forward reaction (mobilization) and the back reaction (deposition). The back reaction in the equilibrium reaction (2) releases the hydrogen halide transport agent, which may be available to drive the mobilization reaction at the source location. This cyclic process leads to a huge increase in the amount of metal transported by the CFT process. In this cyclical transport process, the amount of metal transported is not primarily dependent on the concentration of hydrogen halide in the solar nebula, but rather on the time. The main gas-phase transport mechanism is diffusion, which is favored under conditions of very low total pressure.

In addition to the $\mathrm{HCl}$ cycle, there is also a cyclical transport processes involving HF (Schrön, 2013), and even a cycle involving $\mathrm{HBr}$ may play a minor role (see also Argument 14).

\section{Argument 2: Siderophile elements}

The chemical thermodynamics of solid-gas equilibrium reactions involving the siderophile elements Fe, Ni, Co, Mo, W, Sn, $\mathrm{Ge}$, and Ga exhibit a number of common features. They have a tendency to form gaseous chlorides $\left(\mathrm{FeCl}_{2}, \mathrm{NiCl}_{2}, \mathrm{CoCl}_{2}\right.$,
$\mathrm{MoO}_{2} \mathrm{Cl}_{2}, \mathrm{WO}_{2} \mathrm{Cl}_{2}, \mathrm{SnCl}_{2}, \mathrm{GeCl}_{2}$, and $\mathrm{GaCl}_{3}$ ) with high reactionconditioned pressures $\mathrm{p}_{\mathrm{MeCl}}$ (Figure 1) and positive reaction enthalpies $\Delta H^{0}$ (see Schrön, 1990), which drives thermodynamically directed transport from hotter to colder locations. The joint condensation of these siderophile elements from the gas phase following mobilization and transport of the corresponding gaseous halide therefore appears feasible. This not only demonstrates how nickel-iron bodies can be directly deposited from the gas phase but also goes a long way to explaining the chemical composition of iron meteorites and the minerals they contain. Expressed another way, the CFT model suggests that the chemical composition of irons and their minerals is determined predominantly by the chemical properties of the elements, specifically those properties that influence the formation of gaseous halides. The CFT model also provides a means of defining siderophile elements as those that exhibit a high reaction-conditioned pressure $\mathrm{p}_{\mathrm{MeCl}}$ (reflecting the high chlorine affinity of these elements) in conjunction with a positive reaction enthalpy $\Delta \mathrm{H}^{0}$.

The fact that iron is the most abundant metal and readily reacts with $\mathrm{HCl}$ to form chlorides can make it harder for other siderophile elements to participate in the equilibrium reactions (1) and (2). However, the situation with respect to nickel is somewhat different as is described in Argument 4. The lack of the necessary thermodynamic data means that it is not possible to include the elements $\mathrm{Ru}, \mathrm{Rh}, \mathrm{Pd}, \mathrm{Re}, \mathrm{Os}$, Ir, and Pt in the current analysis. This study assumes that the observed enrichment of siderophile elements in iron meteorites is due primarily to the high reaction-conditioned pressures $\mathrm{p}_{\mathrm{MeCl}}$ of these elements and to the positive reaction enthalpies $\Delta \mathrm{H}^{0}$. The high reactionconditioned pressures $\mathrm{p}_{\mathrm{MeCl}}$ of the elements $\mathrm{Fe}, \mathrm{Ni}, \mathrm{Co}, \mathrm{Mo}, \mathrm{W}$, $\mathrm{Sn}, \mathrm{Ge}$, and $\mathrm{Ga}$ are conveyed in Figure 1. Analogous data for the other siderophile elements are still currently unavailable.

\section{Argument 3: Lawrencite $\mathrm{FeCl}_{2}$}

The primary importance of lawrencite was contested for many years, not least by Buchwald (1971) (in Buchwald, 1975): "Lawrencite appears to be a cosmic ghost that has never been adequately defined in iron meteorites and probably does not exist." More recently, however, information supporting the primary character of lawrencite has been reported (Feng et al., 2012; Lin et al., 2011, see also Schrön, 2013).

In accordance with the discussion presented in Argument 2, the occurrence of the mineral lawrencite $\mathrm{FeCl}_{2}$ in meteorites is regarded in this study as a significant indicator of the effectiveness of the gas-phase transport of $\mathrm{FeCl}_{2}$. Lawrencite is very probably the condensed phase of the gaseous $\mathrm{FeCl}_{2}$ that is transported along a hot to cold gradient and can be deposited as $\mathrm{FeCl}_{2}$ if the back reaction in equilibrium reaction (2) is inhibited. As Schäfer et al. (1956) have argued, this retardation of the back reaction seems plausible when the total pressure is very low, as in that case: "[...]die Diffusionsgeschwindigkeit größer werden als die Geschwindigkeit, mit der sich die heterogenen Gleichgewichte einstellen.” [“[...] the diffusion 
rate may be greater than the rate at which the heterogeneous equilibria become established."]

It is also conceivable that the back reaction in equilibrium reaction (2) could be inhibited due to a scarcity of nickel, as a relative high minimum quantity of nickel needs to be present in iron meteorites for crystallization to occur. In Argument 7, we discuss the minimum nickel concentration in relation to questions regarding stability during crystallization.

\section{Argument 4: Mean average nickel abundances in iron meteorites}

The mean average abundance of nickel in iron meteorites is greater than that in stony-meteorites (Buchwald, 1975). The question is why, when metal and silicate separated, did the nickel prefer to migrate into the metallic phase? One explanation, which relates to the discussion in Argument 2, is provided by the reaction-conditioned pressures of the gaseous metal chlorides $\mathrm{FeCl}_{2}$ and $\mathrm{NiCl}_{2}$. At high temperatures, $\mathrm{p}_{\mathrm{NiCl} 2}$ is greater than $\mathrm{p}_{\mathrm{FeCl}}$ (Figure 1), which indicates that the mobilization of nickel (transition from solid $\mathrm{Ni}$ to gaseous $\mathrm{NiCl}_{2}$ ) is thermodynamically favored compared to the mobilization of $\mathrm{Fe}$ and provides a plausible explanation for the high abundances of nickel observed in iron meteorites and an answer to the questions raised by Saxena (1981) regarding "Fe-Ni abundance in protoplanetary materials" (see also Argument 5).

Furthermore, this thermodynamically driven dominance of nickel over iron at high temperatures is used in the present study to explain the extremely high nickel abundances observed in iron meteorites.

For cobalt, in contrast, there is no such increase in $\mathrm{p}_{\mathrm{CoCl} 2}$ over $\mathrm{p}_{\mathrm{FeCl} 2}$ (see Figure 1) and thus no correspondingly high cobalt content in iron meteorites. The highest Co content in iron meteorites is around 1\%, the highest $\mathrm{Ni}$ abundances are $42 \%$ and $62 \%$. See also Arguments 5 and 7.

\section{Argument 5. Alteration of meteorites by CFT}

If siderophile elements were mobilized from silicate particles in the solar nebula, this must have left at least some traces. Figure 3 shows the situation for germanium. The abundance of germanium in carbonaceous chondrites is approximately that of the solar-system abundance, whereas $\mathrm{H}, \mathrm{L}$, and LL chondrites and the achondrites Aeu, Aho, and some Au contain far less germanium. The solar-system abundances of germanium and a number of other elements are shown in Table 3. Germanium and gallium behave very similarly in this regard. The high abundances of gallium found in C1 chondrites and the E4 enstatite chondrites correspond roughly to the solar-system elemental abundance, whereas the amount of gallium in other chondrites and achondrites is depleted. In contrast, the high cobalt and nickel abundances found in all chondrite groups are similar to the solar-system abundances of these elements (Table 3); only a few individual chondrites have been shown to have lower concentrations. Significantly lower abundances of $\mathrm{Co}$ and $\mathrm{Ni}$ are limited to the groups of achondrites. It therefore seems plausible to argue on the basis of the mobilization processes postulated in the CFT model that the reaction of $\mathrm{HCl}$ with chondrites, achondrites and the nickeliron contained within them could have occurred during a very early stage of accretion, with results that varied widely depending on the specific major and trace elements involved and that this led to measureable reductions in the concentrations of these elements in the source material.

A communication by Fuchs and Olsen in 1973 (in Mason, 1979) is of interest in this regard: " $\mathrm{C} 3$ chondrites contain a little metal, with up to $66 \% \mathrm{Ni}$ and pentlandite with up to $19 \% \mathrm{Ni}$." It seems credible to argue that the small amounts of metal referred to here could well be residual metal inclusions in C3 chondrites that did not undergo CFT mobilization, especially as carbonaceous chondrites do not generally contain nickel-iron.

The abundances of the elements $\mathrm{P}, \mathrm{Cr}, \mathrm{Cu}$, and $\mathrm{Sn}$ in the various meteorite groups also exhibit very characteristic deviations from the solar-system abundances (Table 3).

Reporting on the analysis of tin in silicate meteorites, Mason (1971) remarks on a number of peculiar observations that are potentially explainable by invoking the concept of metal mobilization in accordance with equilibrium reaction (1). He writes: "It is unclear whether the spread is a reflection of the difficulties of the analyses or whether it indicates a lack of tin homogeneity in the meteorites." Tin is one of the elements whose enrichment by CFT in the Earth's crust was demonstrated experimentally very early on (Daubree, 1880 in Schrön, 1994). It seems that the irregularities observed by Buseck (in Mason, 1971) regarding local tin depletion are the result of mineral solubility or are caused by mobilization in accordance with equilibrium reaction (1). Similar depletions are presented in Table 3 for other elements. Further support for this idea is provided by the data for the elements magnesium and scandium, where the meteoritic abundances differ very little from the solar-system abundances. The systematic examination of the propensity of elements to undergo CFT (Schrön et al.,

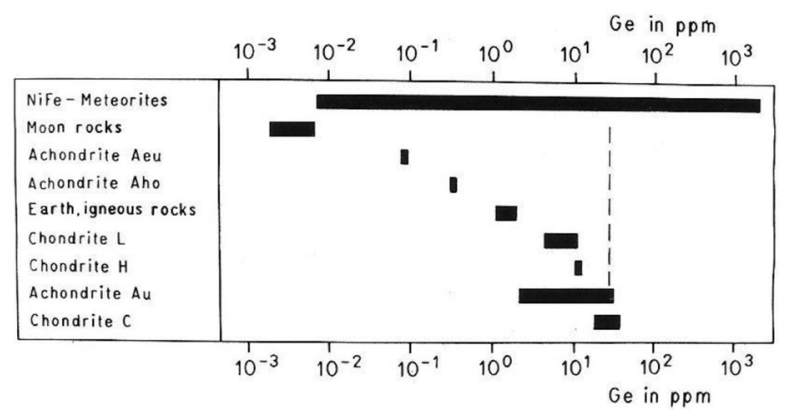

Figure 3. Germanium content of iron and stony meteorites of various classes, moon rocks, and terrestrial igneous rocks. The dashed line shows the solar-system abundance of Ge (Schrön 1989b). 
Table 3. Solar-system abundances of different elements and mean values for the abundances of these elements in different stony meteorite classes, in atoms per million silicon atoms.

\begin{tabular}{|c|c|c|c|c|c|c|c|c|c|c|c|}
\hline & Mg & $\mathbf{P}$ & Sc & $\mathrm{Cr}$ & $\mathrm{Fe}$ & Co & $\mathrm{Ni}$ & $\mathrm{Cu}$ & Ga & Ge & Sn \\
\hline Solar-system abundance & $1,074,000$ & 10,400 & 34.2 & 13,500 & 900,000 & 2250 & 49,300 & 522 & 37.8 & 119 & 3.8 \\
\hline C1 chondrites & $1,060,000$ & 7000 & 31 & 12,700 & 901,000 & 2200 & 47,800 & 540 & 38 & 117 & 3.7 \\
\hline C2 chondrites & $1,040,000$ & 6200 & 35 & 12,400 & 841,000 & 1900 & 44,900 & 390 & 25 & 67 & 1.7 \\
\hline C3 chondrites & $1,060,000$ & 6400 & 36 & 12,300 & 846,000 & 1900 & 41,100 & 300 & 17 & 52 & 0.89 \\
\hline $\mathrm{H}$ chondrites & 965,000 & 5800 & 28 & 10,900 & 812,000 & 2300 & 47,600 & 230 & 12 & 29 & 0.43 \\
\hline L chondrites & 941,000 & 4800 & 28 & 10,900 & 577,000 & 1450 & 32,500 & 220 & 11 & 18 & 0.43 \\
\hline LL chondrites & 934,000 & 4200 & 26 & 10,600 & 536,000 & 1200 & 23,200 & 190 & 10 & 17 & \\
\hline Enstatite chondrites E4 & 727,000 & 11,200 & 25 & 10,100 & 975,000 & 2400 & 52,200 & 430 & 39 & 110 & 2.2 \\
\hline Enstatite chondrites E5.6 & 809,000 & 10,200 & 24 & 9600 & 657,000 & 2100 & 37,700 & 260 & 22 & 60 & 0.82 \\
\hline Aubrites $\mathrm{Ae}$ & $1,000,000$ & 290 & 16 & 1000 & 19,000 & 26 & 330 & 22 & 0.08 & 0.3 & 0.07 \\
\hline Diogenites Ah & 758,000 & 110 & 30 & 22,000 & 254,000 & 37 & 64 & 13 & & & \\
\hline Ureilites Au & $1,370,000$ & 1600 & 26 & 13,800 & 381,000 & 280 & 3300 & 25 & 5.3 & 22 & \\
\hline Howardites Aho & 507,000 & 920 & 53 & 10,200 & 282,000 & 43 & 97 & 13 & 1.8 & 0.5 & \\
\hline Eucrites Aeu & 233,000 & 1500 & 79 & 5400 & 322,000 & 14 & 15 & 5.8 & 2.5 & 0.1 & 0.41 \\
\hline
\end{tabular}

Source: Solar-system abundance data from Anders and Grevesse 1989; stony meteorite data from Mason, 1979

Data values highlighted in blue are greater than $75 \%$ of the relevant solar-system abundance; those values highlighted in yellow are less than $50 \%$ of the solar-system abundance

1988) indicated that scandium would not be transported by this method. There are no known cases of scandium halides undergoing this type of gas-phase transport in nature. Although magnesium forms both $\mathrm{MgCl}_{2}$ and $\mathrm{MgF}_{2}$, the reactionconditioned pressures of these metal halides are too low for CFT to occur (Schrön et al., 1988). In the case of tin, however, the meteoritic abundances are significantly lower than the solar-system abundance and this is interpreted as an indication that the meteorites underwent considerable alteration as a result of CFT. The differences between the meteoritic and solar-system elemental abundances shown in Table 3 suggest that on the basis of the metal mobilization process postulated above as part of the CFT model, the reactions of $\mathrm{HCl}$ with chondrites, achondrites and the metals they contain could play a part in explaining the distribution of elements found in iron meteorites.

Alteration arising from interaction with water vapor is discussed in Argument 10.

\section{Argument 6: Germanium, gallium, and reaction dominance changes involving their chlorides}

The role played by the trace elements germanium and gallium in the classification of irons has received considerable attention (Benedix et al., 2014; Buchwald, 1975; Goldstein et al., 2009; Lovering, Nichiporuk, Chodos, \& Brown, 1957; Mason, 1979; Scott, 1972; Wasson, 1974). As Figure 4 shows, there is excellent correlation between the concentrations of germanium and gallium in octahedrites, hexahedrites, and ataxites $(r=0.91)$.

Germanium and gallium are the only siderophile elements that have several chlorides that are stable in the temperature range applicable to the back reaction in equilibrium reaction (2): $\mathrm{GeCl}_{2}$ and $\mathrm{GeCl}_{4}$ in the case of germanium, and $\mathrm{GaCl}_{3}$ and
$\mathrm{Ga}_{2} \mathrm{Cl}_{6}$ for gallium. $\mathrm{GeCl}_{2}$ and $\mathrm{GaCl}_{3}$ both have positive reaction enthalpies $\Delta \mathrm{H}^{0}$ and are transported according to the CFT model from hot to cooler locations, whereas $\mathrm{GeCl}_{4}$ and $\mathrm{Ga}_{2} \mathrm{Cl}_{6}$ have negative reaction enthalpies and are therefore transported from cold to hot.

At the beginning of the transport process, $\mathrm{GeCl}_{2}, \mathrm{GaCl}_{3}$, and the chlorides of other siderophile elements migrate from hot to cold. Subsequently in slightly cooler regions, there is a change in the dominant reaction, and $\mathrm{GeCl}_{4}$ and $\mathrm{Ga}_{2} \mathrm{Cl}_{6}$ become the dominant chlorides (see Figures 1 and 2). The dominance change $\mathrm{GeCl}_{2} / \mathrm{GeCl}_{4}$ results in local enrichment in germanium, as the dominant chloride $\mathrm{GeCl}_{4}$ will now have a tendency to be transported back to a hotter location. Gallium behaves analogously (see Schrön, 2013). The temperature range in which the

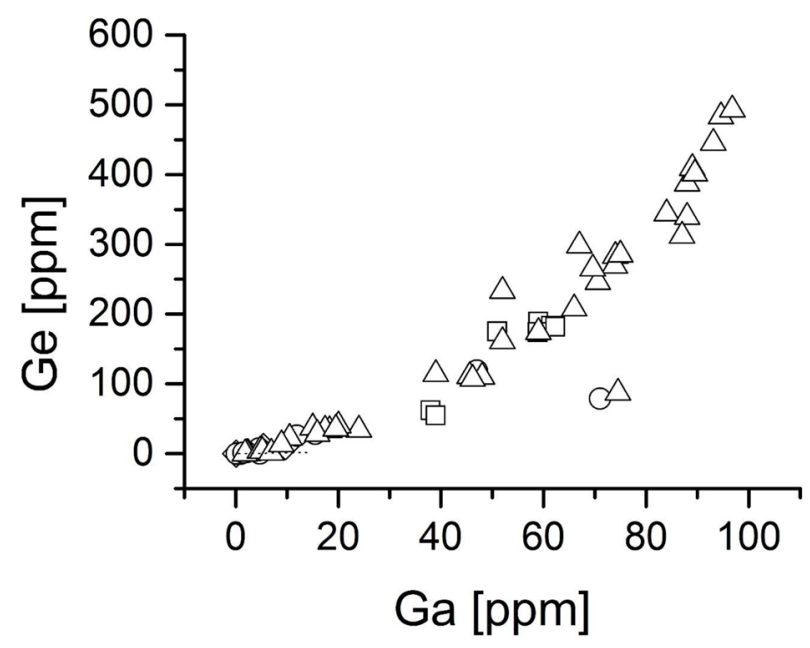

Figure 4. Linear plot Ge against Ga for iron meteorites without plessitic octahedrite Butler (data from Table 2). $r=0.91$, $\Delta$ octahedrites, $\square$ hexahedites, $\bigcirc$ ataxites, $\diamond$ anomalous. 
$\mathrm{GeCl}_{2} / \mathrm{GeCl}_{4}$ reaction dominance change occurs also happens to be the preferred temperature range for the back reaction in equilibrium reaction (2) in which the gaseous metal chlorides of siderophile elements react, releasing $\mathrm{HCl}$ and depositing the original metal. Thus, in the temperature range in which the back reaction is favored, there is an accompanying enrichment in the concentration of gaseous germanium chlorides. This fact offers an explanation for the frequent incidence of very high germanium abundances in iron meteorites (Figure 3). A similar situation is found for gallium, though the temperature at which the $\mathrm{GaCl}_{3} / \mathrm{Ga}_{2} \mathrm{Cl}_{6}$ switch occurs does not lie directly in the middle of the temperature range for the back reaction, as is the case with germanium. In the case of copper, the temperature at which the reaction dominance change $\mathrm{CuCl} / \mathrm{Cu}_{3} \mathrm{Cl}_{3}$ occurs is above the temperature range that favors the back reaction (Figure 1); for tin, the $\mathrm{SnCl}_{2} / \mathrm{SnCl}_{4}$ dominance change occurs at temperatures significantly lower than the temperature range in which the back reaction is favored (Figure 2).

There is a further important difference between Ge and Ga on the one hand and $\mathrm{Fe}, \mathrm{Ni}, \mathrm{Co}, \mathrm{Cu}$ and $\mathrm{Cr}$ on the other. In contrast to the other siderophile elements, germanium and gallium have substantially higher saturation vapor pressures $\mathrm{p}_{\text {MeX }}^{\text {s }}$. These higher saturation vapor pressures mean that the thermodynamically controlled transport of germanium or gallium can still occur at lower temperatures. This strengthens the germanium and gallium enrichment mechanism driven by reaction dominance changes, while also explaining why there are some iron meteorites with extremely low germanium concentrations.

\section{Argument 7: Cobalt, nickel and their relationships to germanium and gallium}

The correlation between the elements nickel and cobalt is shown in Figure $5(r=0.51)$. The difference between the correlation found between the elements germanium and

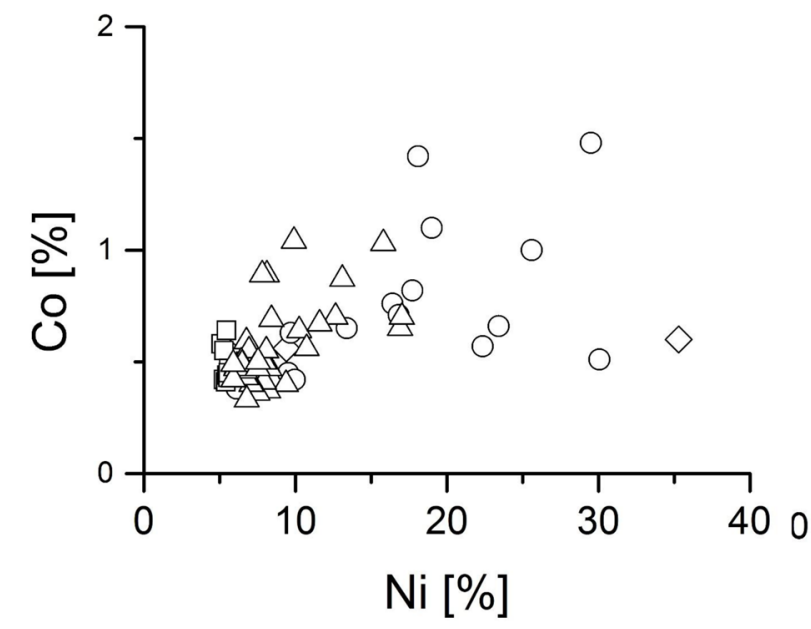

Figure 5. Linear plot Co against $\mathrm{Ni}$ for iron meteorites (data from Table 2). $r=0.51$. $\Delta$ octahedrites, $\square$ hexahedites, $\bigcirc$ ataxites, $\diamond$ anomalous. gallium (see Figure 4) and that between the elements nickel and cobalt (Figure 5) therefore requires explanation as do the minimum abundances of nickel $(5.1 \%)$ and cobalt $(0.32 \%)$ typically observed in irons (Buchwald, 1975).

The behavior observed for nickel and cobalt is due to a number of factors:

(1) Similar mobilization of the elements $\mathrm{Fe}, \mathrm{Ni}$, and $\mathrm{Co}$ in equilibrium reaction (1), as evidenced by the solarsystem abundances shown in Table 3,

(2) Similar mobilization of the elements $\mathrm{Fe}, \mathrm{Ni}$, and Co in equilibrium reaction (2),

(3) Similar reaction-conditioned pressures $\mathrm{p}_{\mathrm{MeX}}$ and a similar temperature dependence of the reactionconditioned pressures of the chlorides of the elements $\mathrm{Fe}, \mathrm{Ni}$, and Co (see Figure 1) and

(4) Crystallographic effects that influence the minimum quantities of nickel and cobalt in iron meteorites or that are themselves influenced by these minimum abundances.

The minimum abundances of nickel and cobalt in iron meteorites are also related to the iron/nickel and nickel/ cobalt ratios. According to Buchwald (1975), the average Fe : Ni ratio in the solar photosphere is 17.8 and in ordinary chondrites 19.5, both similar to the value of 17 observed for the $\mathrm{Ni}$ : Co ratio in chondrites. Based on the published minimum abundance of $5.1 \% \mathrm{Ni}$ in iron meteorites, the Fe : Ni ratio is calculated to be $18.6(94.9 / 5.1=18.6)$. Similarly, the minimum abundance of cobalt in iron meteorites yields a $\mathrm{Ni}$ : Co ratio of $19(6.08 / 0.32=19)$ or 20.6 in the case of the Om Clark County iron meteorite $(6.79 / 0.33=20.6)$. Is this mere coincidence? With the exception of four values, all of the $\mathrm{Ni}$ : Co ratios that can be calculated from the data in Table 2 lie between 8.5 and 26 (Figure 6). The uniform rise in the $\mathrm{Ni}$ : Co ratios observed in Figure 6 hides a number of interesting

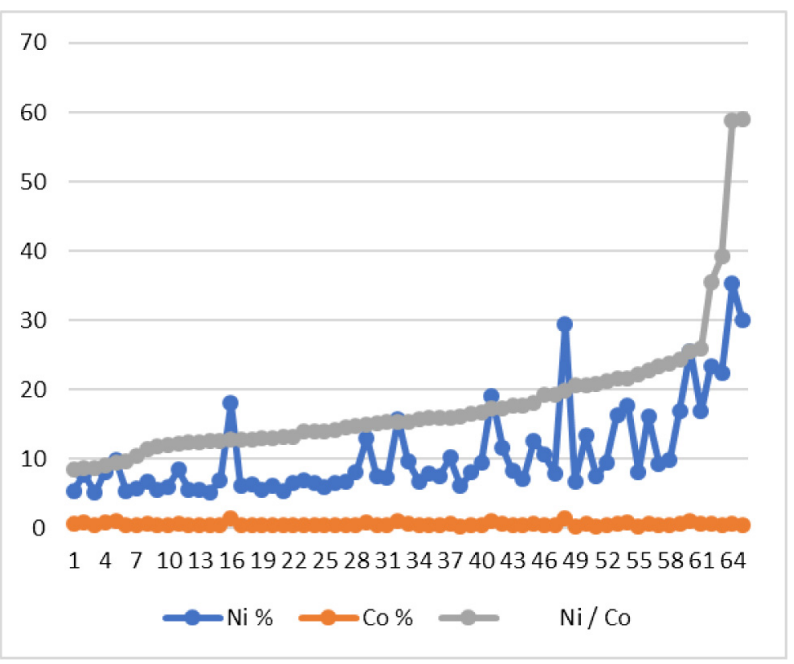

Figure 6. Nickel/cobalt ratios in iron meteorites. Data from Table 2. 
features, such as the combination of almost identical absolute abundances with different $\mathrm{Ni}$ : Co ratios. (e.g. for meteorites with a cobalt abundance of 1\%: Om Thurlow 9.9/1.04= 9.5, Ataxite Ternera 18.1/1.42=12.7, $O_{\text {plessitic }}$ Butler 15.8/ 1.03=15.3, Ataxite Morradal 19/1.1=17.3, Ataxite Lime Creek 29.5/1.48=19.9 and Ataxite San Cristobal 25.6/1=25.6).

In contrast, the remaining four $\mathrm{Ni}$ : Co ratios in Figure 6 are extremely high: Ataxite Freda 23.41/0.66=35.5, Ataxite Wedderburn 22.36/0.57=39.2, Anomalous Santa Catharina 35.3/0.6=58.8 and Ataxite Twin City 30.06/0.51=58.9. Interestingly, these $\mathrm{Ni}$ : Co ratios are very nearly exactly twice (39.2) or three times (58.8) as large as 19.6. The reason for these multiples, which occur predominantly in ataxites, seems to be the upper limit for cobalt in iron meteorites (see Argument 4). The astonishing aspect is the apparent memory effect regarding the $\mathrm{Ni}$ : Co ratio of 19.6. There does not seem to be any direct relationship with the abundance ratios in chondrites that were discussed above. But a $\mathrm{Ni}$ : Co ratio very close to 19.6 appears to be a characteristic feature of numerous iron meteorites (e.g. Oplessitic Monahans 10.75/ $0.56=19.2$, Of Gibeon 7.93/0.41=19.3, Ataxite Lime Creek $29.5 / 1.48=19.9$ ). Why should this element ratio of 19.6 be so significant?

In this study, we argue that these findings are a reflection of the dominant role that the chemical and physical laws of crystallography play during the formation of iron meteorites. There is obviously a connection between, on the one hand, the iron/nickel ratios, the nickel/cobalt ratios and the minimum $\mathrm{Ni}$ and Co contents in iron meteorites, and, on the other hand, the body-centered cubic lattice of kamacite, the atomic radii (Fe 124.1 pm, Ni 124.6 pm, Co 125.3 pm) and other relevant properties or energy states of the participating atoms that results in the high stability of kamacite and excludes the formation of other minerals with lower minimum nickel and cobalt contents.

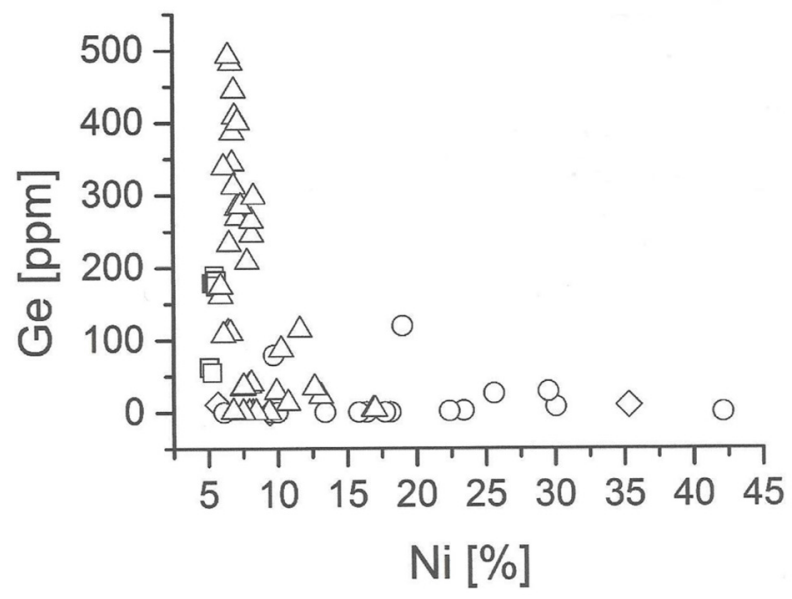

Figure 7. Linear plot $\mathrm{Ge}$ against $\mathrm{Ni}$ for iron meteorites without plessitic octahedrite Butler (data from Table 2). $r=0.5$ $\Delta$ octahedrites, $\square$ hexahedites, $\bigcirc$ ataxites, $\diamond$ anomalous.
Table 4. Nickel and copper concentration data for iron meteorites exhibiting dual concentration values for $\mathrm{Cu}$ (selected data from Table 1).

\begin{tabular}{|c|c|c|c|c|c|}
\hline Meteorite & Class & $\begin{array}{l}\mathrm{Ni} \\
\%\end{array}$ & $\begin{array}{c}\mathrm{Cu} \\
\mathrm{ppm}\end{array}$ & $\mathrm{Cu} / \mathrm{Ni}$ & $\begin{array}{l}\mathrm{Cu} / \mathrm{Ni} \\
\text { Group }\end{array}$ \\
\hline $\begin{array}{l}\text { Bellsbank } \\
\text { South Africa }\end{array}$ & $\mathrm{H}$ & 5.3 & 500 & $9.43 \mathrm{E}-03$ & IV \\
\hline $\begin{array}{l}\text { Bellsbank } \\
\text { South Africa }\end{array}$ & $\mathrm{H}$ & 5.3 & 200 & $3.77 \mathrm{E}-03$ & \\
\hline $\begin{array}{l}\text { Walker County } \\
\text { Alabama USA }\end{array}$ & $\mathrm{H}$ & 5.46 & 600 & $1.10 \mathrm{E}-02$ & IV \\
\hline $\begin{array}{l}\text { Walker County } \\
\text { Alabama USA }\end{array}$ & $\mathrm{H}$ & 5.46 & 120 & $2.20 \mathrm{E}-03$ & III \\
\hline Braunau Bohemia & $\mathrm{H}$ & 5.49 & 700 & $1.28 \mathrm{E}-02$ & IV \\
\hline Braunau Bohemia & $\mathrm{H}$ & 5.49 & 131 & $2.39 \mathrm{E}-03$ & III \\
\hline $\begin{array}{l}\text { Sandia Mountains } \\
\text { New Mexico USA }\end{array}$ & Ogg & 5.9 & 800 & $1.36 \mathrm{E}-02$ & IV \\
\hline $\begin{array}{l}\text { Sandia Mountains } \\
\text { New Mexico USA }\end{array}$ & Ogg & 5.9 & 123 & $2.08 \mathrm{E}-03$ & III \\
\hline $\begin{array}{l}\text { Silver Bell } \\
\quad \text { Arizona USA }\end{array}$ & Ogg & 6.43 & 500 & $7.78 \mathrm{E}-03$ & IV \\
\hline $\begin{array}{l}\text { Silver Bell } \\
\text { Arizona USA }\end{array}$ & Ogg & 6.43 & 110 & $1.71 \mathrm{E}-03$ & III \\
\hline Duchesne Utah USA & Of & 9.37 & 127 & $1.36 \mathrm{E}-03$ & III \\
\hline Duchesne Utah USA & Of & 9.37 & 800 & $8.54 \mathrm{E}-03$ & IV \\
\hline $\begin{array}{l}\text { Deep Springs N } \\
\text { Carolina USA }\end{array}$ & Ataxite & 13.4 & 7.8 & $5.82 \mathrm{E}-05$ & II \\
\hline $\begin{array}{l}\text { Deep Springs N } \\
\text { Carolina USA }\end{array}$ & Ataxite & 13.4 & 300 & $2.24 \mathrm{E}-03$ & III \\
\hline Tlacotepec Mexico & Ataxite & 16.2 & 10 & $6.17 \mathrm{E}-05$ & II \\
\hline Tlacotepec Mexico & Ataxite & 16.2 & 900 & $5.56 \mathrm{E}-03$ & \\
\hline $\begin{array}{l}\text { Hoba Grootfontein } \\
\text { SW Africa }\end{array}$ & Ataxite & 16.41 & 300 & $1.83 \mathrm{E}-03$ & III \\
\hline $\begin{array}{l}\text { Hoba Grootfontein } \\
\text { SW Africa }\end{array}$ & Ataxite & 16.41 & 1.3 & $7.92 \mathrm{E}-06$ & 1 \\
\hline $\begin{array}{l}\text { Santa Catharina } \\
\text { Brazil }\end{array}$ & Anomalous & 35.3 & 850 & $2.41 \mathrm{E}-03$ & III \\
\hline $\begin{array}{l}\text { Santa Catharina } \\
\text { Brazil }\end{array}$ & Anomalous & 35.3 & 1500 & $4.25 \mathrm{E}-03$ & \\
\hline
\end{tabular}

Group I: 7.9-8E-06, Group II: 5.6-6.3E-05, Group III: 1.2-3.3E-03, Group IV: 7.8E-03-1.7E-02.

The relationship between germanium abundance and nickel abundance shown in Figure 7 clearly demonstrates that ataxites predominantly exhibit high quantities of nickel but low levels of germanium. The quantity of germanium is generally observed to increase as one progresses along the series ataxites, Of, Off, $\mathrm{Om}, \mathrm{Ogg}, \mathrm{H}$, and $\mathrm{Og}$. A very similar general trend, that is, also with numerous overlapping regions, is found for decreasing nickel abundances, with one exception, namely, that the very lowest nickel abundances are found in hexahedrites. It therefore seems reasonable to suggest that the series ataxites, Of, Off, Om, $\mathrm{Ogg}, \mathrm{H}$, and $\mathrm{Og}$, might be related to differing temperatures of formation. According to the view presented in the current study, ataxites were deposited directly from the gas phase via equilibrium reaction (2) at temperatures higher than those for other iron meteorites (see Argument 12). This would seem to suggest that decreasing germanium and gallium abundances or increasing nickel abundances in iron meteorites indicate increasing temperatures of formation. The exceptional position held by the 
hexahedrites may be the result of temporal aspects. The iridium values in iron meteorites (Table 2) indicate that answers to such open questions may be available as soon as reaction-conditioned pressure data is available for iridium (see also Argument 2). Following Sahijpal, Soni, \& Gagan, 2007, it is assumed that the decay of the short-lived radioactive nuclides ${ }^{26} \mathrm{Al}$ and ${ }^{60} \mathrm{Fe}$ is the heat source during accretion that gradually heats up smaller particles. Although these ideas are highly speculative, they are reasonable when one realizes that during the process of formation of iron meteorites by CFT, accretion was continuing and the larger particles that developed offered a better chance of achieving the relatively high temperatures that mobilization (i.e. the forward reaction in equilibrium reaction (2)) requires. When a metal deposits (back reaction in equilibrium reaction (2)) and is incorporated into the octahedrite, hexahedrite, or ataxite structure in accordance with crystallographic principles, the mobilized metal chlorides from which the metals deposit will have had very different spatial and temporal histories (mobilization via equilibrium reaction (1) or (2), differing mobilization temperatures, and in some cases the effects of reaction dominance change). This model of iron meteorite formation could therefore be seen as providing an explanation for the numerous, in some cases confusing and contradictory, correlation diagrams presented by numerous authors (Buchwald, 1975; Lovering et al., 1957; Mason, 1979; Scott, 1972; Wedepohl, 1970/1972).

\section{Argument 8: Chromium, copper, and dual-concentration values}

The abundances of chromium and copper in iron meteorites can be used to support the idea that the observed nickel concentrations are related to the temperature of formation, particularly in view of the fact that there is a relatively good correlation known to exist between nickel and copper abundances (Scott, 1972, Figure 15). Iron meteorites exhibit a very wide range of abundances of the elements chromium and copper. High abundances of chromium are not found whenever the abundances of germanium and gallium are high; they are associated with low Ge and Ga content and are therefore often found in ataxites (Figure 8). This observation accords with the reaction-conditioned pressures computed for $\mathrm{CrCl}_{2}$. The reaction-conditioned pressure of $\mathrm{CrCl}_{2}$ is relatively low and only achieves the values necessary for gas-phase transport at high temperatures (see Figure 1). It is also apparent that there are numerous cases in which two concentrations of chromium have been recorded in one and the same iron meteorite $(60 /$ $1650 \mathrm{ppm}$ in anomalous N'Goureyma, 73/2600 ppm in ataxite Arltunga, $168 / 310 \mathrm{ppm}$ in ataxite Tlacotepec, 44/500 ppm in H Walker County, 25/200 ppm in Ogg Sandia Mountains). A similar phenomenon has been observed for copper (see Tables 2 and 4). Dual-concentration values have been recorded for chromium and for copper in the meteorites Ogg Sandia Mountains, ataxite Tlacotepec, and in $\mathrm{H}$ Walker County (Table 2). The ratio of the higher concentration to the lower concentration in these dual values is greatest in the ataxites. In the

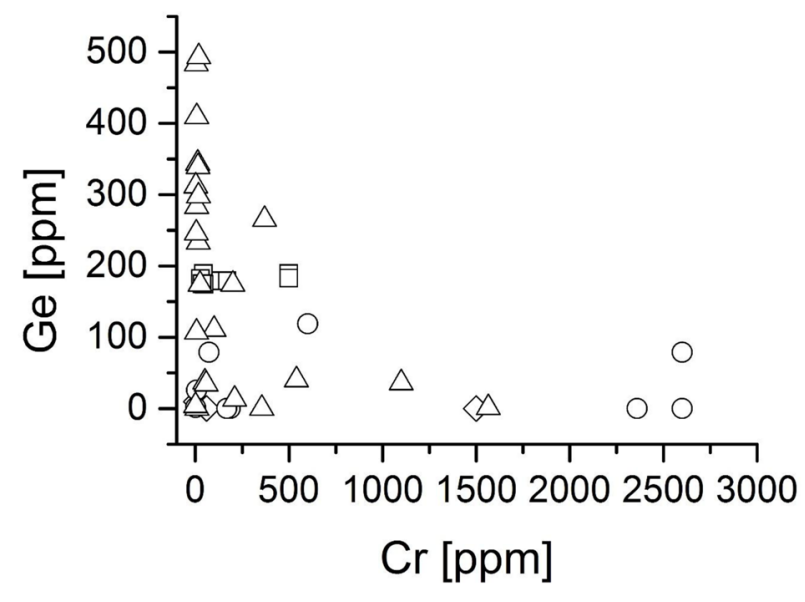

Figure 8. Linear plot $\mathrm{Ge}$ against $\mathrm{Cr}$ for iron meteorites without plessitic octahedrite Butler (data of Table 2). $r=0.34$, $\Delta$ octahedrites, $\square$ hexahedites, $\bigcirc$ ataxites, $\diamond$ anomalous.

case of copper, the three ataxites yield ratios of 38, 90, and 230; for chromium the ratios are 25 and 35 (ataxtite and anomalous ataxite). The ratios recorded in other groups of iron meteorites are only 1.8 and 11 for copper and chromium, respectively.

These dual-concentrations have not been found for other elements. One factor that may help explain these observations is that for both chromium and copper, the thermodynamically driven transport process in the CFT model can be influenced very easily. For $\mathrm{CrCl}_{2}$, the reaction-conditioned pressure required for transport is only achieved at high temperatures. The dominance change in $\mathrm{CuCl} / \mathrm{Cu}_{3} \mathrm{Cl}_{3}$ occurs at the hightemperature limit of the temperature window for the metal deposition in equilibrium reaction (2). If the temperature is not high enough for the $\mathrm{CuCl} / \mathrm{Cu}_{3} \mathrm{Cl}_{3}$ dominance change, the associated enrichment does not occur and back reaction therefore results in the deposition of smaller quantities of copper. In both cases, gas-phase transport will be influenced by only small changes in temperature, and this could explain the occurrence of the dual-concentration values found for chromium and copper in iron meteorites. The explanation is even simpler if it is assumed that the accreting particles involved in the reaction were at different temperatures.

On the basis of these observations and the results of this study, the geochemical character of the elements chromium and copper will vary depending on the temperature of formation of the iron meteorites: at high temperatures and thus correspondingly high reaction-conditioned pressures, both elements can be assigned siderophile character.

The relatively frequent occurrence of dual-concentration values for copper within a single iron meteorite is also noteworthy because these dual-copper concentrations can be classified into groups exhibiting similar $\mathrm{Cu}$ : Ni ratios (Table 4). When plotted in a log-log diagram, the pairs of $\mathrm{Cu}-\mathrm{Ni}$ concentration values appear to obey an approximately linear relationship (Figure 9). These groups are also able to incorporate practically all of the other iron meteorites studied here 


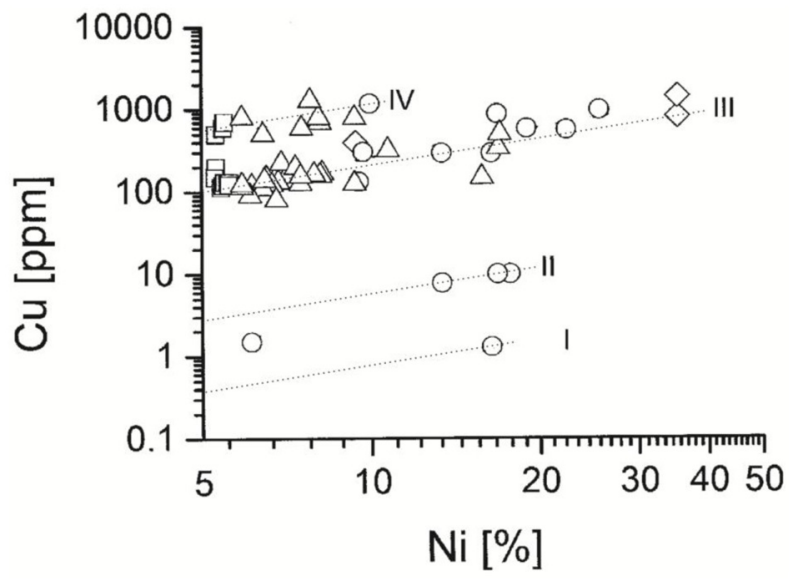

Figure 9. Logarithmic plot $\mathrm{Cu}$ against $\mathrm{Ni}$ for iron meteorites (data from Table 2, incl. dual-concentration values for $\mathrm{Cu}$ ); $\Delta$ octahedrites, $\square$ hexahedites, $\bigcirc$ ataxites, $\diamond$ anomalous; Group I: ataxite Hoba (low $\mathrm{Cu}$ value); Group II: 3 ataxites with low $\mathrm{Cu}$ / Ni ratio; Group III: main group with 7 H, 2 Of, 3 Off, 3 Om, 10 Og, 5 Ogg, 1 0, 6 ataxites, 1 anomalous; Group IV: 3 H, 1 Of, 3 Om, 1 Og, 2 Ogg, 1 ataxite (Table 4).

with their associated copper concentrations (Table 2). Seven of the dual-concentration values for copper in Table 4 are in two different groups, five of them in Groups III and IV. In the case of the Hoba ataxite meteorite, the higher copper concentration is assigned to Group III, while the lower value is the only member of Group I.

\section{Argument 9: Ge/Ga-groups, $\mathrm{Cu} / \mathrm{Ni}$-groups, and isomorphism}

As described in the previous section, the dual-concentration values found for chromium and copper can be classified into groups. The elements germanium and gallium also exhibit evidence for this type of group formation. This classification into groups is shown clearly in Figure 10, which is a log-log plot of germanium versus gallium abundances. Note how the germanium-rich plessitic octahedrite Butler, which would typically be considered a statistical outlier, is incorporated harmoniously into the classification scheme as the single sample belonging to Group IV. Out of a total of 70 meteorites, 66 can be classified according to the Ge/Ga groups defined in Table 2. The iron meteorites with Ge:Ga ratios close to unity are the ataxites Freda and Wedderburn and they are classified as belonging to Group III. Group II contains six ataxites and one anomalous meteorite; Group I contains one ataxite (Tucson) and five Of. The $\mathrm{Ge} / \mathrm{Ga}$ groups and the $\mathrm{Cu} / \mathrm{Ni}$ groups also exhibit certain common features. For example, the three ataxites Weaver Mountains, Deep Springs, and Tlacotepec all belong to Group II in the Ge/Ga classification scheme and to Group II in the $\mathrm{Cu} / \mathrm{Ni}$ classification scheme; Of Wood's Mountain, of Obernkirchen, and the ataxite Tucson are all in Group I in the $\mathrm{Ge} / \mathrm{Ga}$ classification system and are also all in Group III within

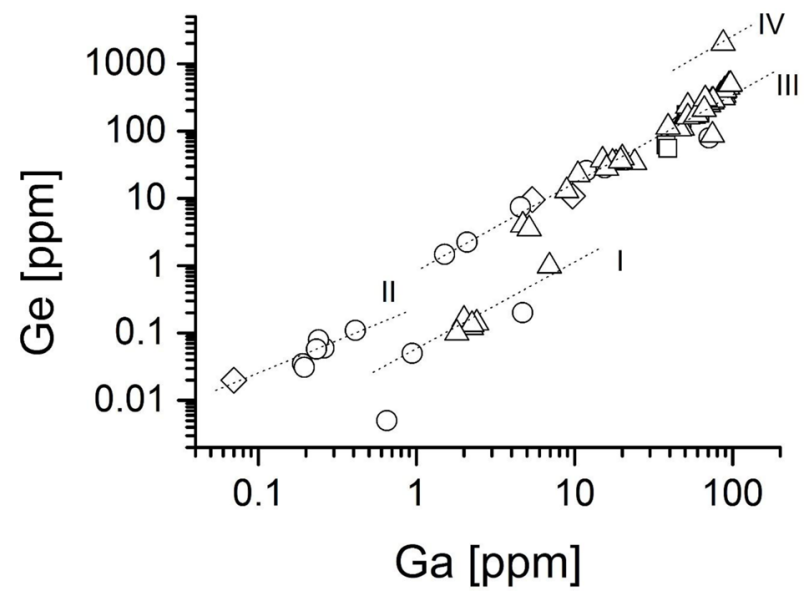

Figure 10. Logarithmic plot Ge against $\mathrm{Ga}$ for iron meteorites (data from Table 2); $\Delta$ octahedrites, $\square$ hexahedites, $\bigcirc$ ataxites, $\diamond$ anomalous; Group I: 1 ataxite and 5 Of with very low Ge/Ga ratio; Group II: 6 ataxites and 1 anomalous with low Ge/Ga ratio; Group III main group Ge/Ga ratio 0.8-5.1 with 7 ataxites, 2 anomalous, 1 Off, 2 Of, 8 Om, 9 H, 2 Oplessitic, 14 Og, 7 Ogg; Group IV: $\mathbf{O}_{\text {plessitic }}$ Butler.

the $\mathrm{Cu} / \mathrm{Ni}$ categorization scheme. This is interpreted here as an indication of the effectiveness of a higher-lying law.

The unexpected regularity and the excellent correlation observed in the $\mathrm{Ge} / \mathrm{Ga}$ and the $\mathrm{Ni} / \mathrm{Cu}$ classification schemes may be related to electric charge effects during metal crystallization, as the elements are in different oxidation states $\left(\mathrm{Fe}^{\mathrm{II}}, \mathrm{Ni}^{\mathrm{II}}, \mathrm{Cu}^{\mathrm{I}}, \mathrm{Ga}^{\mathrm{III}}, \mathrm{Ge}^{\mathrm{IV}}\right.$ ) prior to undergoing deposition via the back reaction in equilibrium reaction (2). Differences in electric charge densities may well influence element distribution during the crystallization process that is associated with metal deposition via the back reaction and thus play a role in determining correlations in the concentrations of elements in iron meteorites. The distribution of the elements nickel and cobalt in iron meteorites do not exhibit the same regularity and strong correlation found between germanium and gallium and between copper and nickel. The oxidation states of cobalt and nickel (and iron) are all identical and there are therefore no differences in charge density that require compensation.

In summary, the excellent correlation observed between germanium and gallium in iron meteorites is the result of (1) the similarity of the mobilization processes for germanium and gallium (Argument 5), (2) the enrichment of germanium and gallium due to the dominance change behavior of both elements in the temperature range favorable to the back reaction of chlorides of siderophile elements (Argument 7), and (3) crystallographic rules governing isomorphism that describe how charge differences between $\mathrm{Ga}^{\mathrm{III}}, \mathrm{Ge}^{\mathrm{IV}}$ and the major elements $\mathrm{Fe}, \mathrm{Ni}$, Co (all in oxidation state II) effect how the gas-phase germanium and gallium ions are deposited as metals into the solid crystal lattice.

A similar explanation applies to the dual concentration values observed for copper and chromium. The variations in the 
chromium and copper concentrations in iron meteorites are interpreted as the effect of temperature changes on the CFT process (Argument 8). The group classification scheme for the dual concentration values recorded for copper and the observed correlations are considered to be due to isomorphism (charge differences among the three metal ions $\left(\mathrm{Cu}^{\mathrm{I}}, \mathrm{Ni}^{\mathrm{II}}, \mathrm{Fe}^{\mathrm{II}}\right)$ influencing the back reaction, that is, how the gas-phase ions deposit as solid metals).

\section{Argument 10: Metal-silicate separation}

Metal-silicate separation during accretion in the early solar system has been the subject of much scientific discussion. Driven by a desire to address certain key planetological problems, Urey (1952), Suess (1965), Anders (1969), Grossman and Larimer (1974), and Saxena (1981) all tried in vain to discover a simple process by which metals and silicates separated during accretion. No such process has so far been found. If the CFT model is applied to this problem, the separation of metals from silicates can be explained in terms of a number of sub-processes: (1) the reduction of oxides (the term "reduction" is used here to mean the removal of oxygen) in accordance with equilibrium reaction (1) and (2) the activation of metallic phases already present in the solar nebula in accordance with equilibrium reaction (2). Both of these sub-processes yield metal halides that are transported from hotter to cooler locations where they then in the third sub-process (3) are deposited as metals via the back reaction in equilibrium reaction (2). As a result, the various metal halides of siderophile elements generated by reduction and activation can all jointly deposit their metals. Sorting effects that occur during transport and the crystallographic principles governing crystallization lead to the formation of numerous nickel-iron bodies of the types octahedrite, hexahedrite, and ataxite with their associated properties. The reduction of oxides in accordance with equilibrium reaction (1) involves the release of oxygen in the form of water vapor into the solar nebula. The reduction stage is an important step in the separation of metal and silicate in the CFT model proposed here. The water vapor that is released may well cause the sort of meteorite alterations that have been observed by numerous authors. For instance, Goldstein et al. (2009), reporting on the Hf-W metal-silicate fractionation ages of CAIs, state: "[...] aqueous fluids have caused alteration in Allende."

The activation of metal phases present in the solar nebula according to equilibrium reaction (2) may require a distinction to be made between two variants: (1) the mobilization via reaction of heated metal inclusions from chondrites or similar bodies (see also Argument 5) and (2) the reaction with condensing still hot metal particles in the solar nebula. If that is indeed the case, there would be a second source of heat and thus an additional "motor" for driving CFT. In the condensation model discussed by Davis and Richter (2014), iron condenses as $\mathrm{Fe}-\mathrm{Ni}$ metal after the formation of CAIs, that is, at a relatively advanced stage of accretion in which the mineral aggregates are several millimeters in size or larger.
This may be the stage of accretion during which CFT is most favored. It is worth noting in this regard that in their numerous publications on iron droplets, Friedrich et al., (2015) support the idea that these grains were formed via condensation, that is, are nebular in origin.

There is no logical reason why the reduction of oxides (equilibrium reaction (1)) could not also be associated with the condensation processes occurring in a cooling gas of cosmic composition. Indeed, this would simplify the question of the heat source required to drive the CFT process. In this version of events, CFT would shift in time, possibly beginning before the formation of CAIs.

Observations made by Keil (1968) are also of interest when attempting to characterize the process of metal-silicate separation. "E4, E5 and E6 chondrites have an average of 3.2, 3.3 and $1.3 \% \mathrm{Si}$ in their nickel-iron, but most iron meteorites contain only trace amounts of silicon." The differences discussed above between iron meteorites and the nickel-iron of the stony-iron meteorites are reinforced by the different abundances of silicon observed by Keil. Also of relevance to the metal-silicate separation problem is the remark made by Urey (1952): “[...] the stones usually contain some amount of metal phase though the irons have no silicate phase."

\section{Argument 11: Schreibersite, troilite, kamacite/taenite, and their equilibrium constants $K_{p}$}

The differences in the stability of minerals may also play a part in the formation of meteorites by CFT. This is exemplified here by analyzing the case of the minerals kamacite/taenite $\mathrm{Fe}-\mathrm{Ni}$, troilite $\mathrm{FeS}$, and schreibersite $\mathrm{Fe}_{3} \mathrm{P}$. Siderophile elements play a key role in the formation of these three minerals (see Argument 2). The formation of kamacite/taenite can be described by the back reaction in equilibrium reaction (6) (see page 4).

The formation of troilite can be described by the back reaction in equilibrium reaction (7):

$$
\text { FeS,s }+2 \mathrm{HCl}, \mathrm{g} \leftrightarrow \mathrm{FeCl}_{2}, \mathrm{~g}+\mathrm{H}_{2} \mathrm{~S}, \mathrm{~g}
$$

The formation of schreibersite can be described by the back reaction in equilibrium reaction (8):

(8) $\mathrm{Fe}_{3} \mathrm{P}, \mathrm{s}+6 \mathrm{HCl}, \mathrm{g}+5 \mathrm{HF}, \mathrm{g} \leftrightarrow 3 \mathrm{FeCl}_{2}, \mathrm{~g}+\mathrm{PF}_{5}, \mathrm{~g}+5,5 \mathrm{H}_{2}, \mathrm{~g}$

The temperature-dependent equilibrium constants $\mathrm{K}_{\mathrm{p}}$ indicate the extent to which the corresponding back reactions that lead to deposition of the mineral from the gas phase are favored. The deposition of kamacite/taenite (equilibrium reaction (6)) begins when the temperature falls below the computational temperature threshold of $2000 \mathrm{~K}$ (the data presented in Table 1 indicate trends rather than absolute values) and becomes thermodynamically favored as the temperature decreases (see $K_{p} 6$ in Table 1). The same behavior, though in this case even more pronounced, is expected for the 
formation of troilite. The values for $K_{p} 7$ in Table 1 show troilite deposition commences at temperatures that are lower than those for kamacite or taenite formation and this process is therefore thermodynamically favored at lower temperatures compared to kamacite or taenite deposition. Troilite can therefore be formed together with nickel-iron in the solar nebula provided that $\mathrm{H}_{2} \mathrm{~S}$ is present. But where does the necessary $\mathrm{H}_{2} \mathrm{~S}$ come from? According to Schrön (1989b), the following gas-phase equilibrium (9)

$$
\mathrm{SO}_{2}, \mathrm{~g}+\mathrm{H}_{2}, \mathrm{~g} \leftrightarrow \mathrm{H}_{2} \mathrm{~S}, \mathrm{~g}+\mathrm{O}_{2}, \mathrm{~g}
$$

lies far to the right under cosmochemical conditions both at very low and at very high temperatures $(2000 \mathrm{~K})$, demonstrating the far greater stability of $\mathrm{H}_{2} \mathrm{~S}$ compared to $\mathrm{SO}_{2}$. It is assumed that the observed differences in chemical compositions of cosmic and terrestrial FeS (terrestrial troilites contain less iron) can be explained by the different mechanisms of mineral genesis (cosmic CFT vs. terrestrial igneous). The formation of troilite in the solar nebula has also been the subject of experimental investigations (Tachibana \& Tsuchiyama, 1998), though these studies did not involve any assumptions of gas-phase $\mathrm{FeCl}_{2}$ transport.

The formation of schreibersite according to equilibrium reaction (8) is even more strongly thermodynamically favored than the formation of troilite. According to currently held views, schreibersite formation requires the presence of $\mathrm{PF}_{5}$ or HF. As soon as HF is present in an environment in which the metal chloride gas-phase transport processes described here occur, $\mathrm{PF}_{5}$ will be formed preferentially and will react immediately with the iron chloride to redeposit schreibersite $\mathrm{Fe}_{3} \mathrm{P}$ via the back reaction. The magnitude of the equilibrium constant $K_{p} 8$ (Table 1 ) indicates that the back reaction will be favored over the back reactions in equilibrium reactions (6) and (7). Consequently, schreibersite will be preferentially deposited before troilite or kamacite/taenite at all conceivable temperatures. Therefore, as soon as $\mathrm{PF}_{5}$ is present in the deposition zone, the formation of kamacite and taenite, for example, will be suppressed as schreibersite deposition prevails, as the elements needed to form schreibersite are already present as their chlorides. The dominance of the back reaction in equilibrium reaction (8) suggests that it may influence the formation of rhabdite or that it may explain the metasomatic genesis of rhabdite, which requires only the sporadic availability of small amounts of $\mathrm{PF}_{5}$. It may also be the case that - like schreibersite - the rare mineral roaldite is formed by direct deposition from the gas phase according to reaction (10):

(10) $\mathrm{Fe}_{4} \mathrm{~N}, \mathrm{~s}+8 \mathrm{HCl}, \mathrm{g}+3 \mathrm{HF}, \mathrm{g} \leftrightarrow 4 \mathrm{FeCl}_{2}, \mathrm{~g}+\mathrm{NF}_{3}, \mathrm{~g}+5,5 \mathrm{H}_{2}, \mathrm{~g}$.

In the presence of calcium, a further displacement reaction involving phosphorous-containing minerals may occur, with preferential formation of apatite. As indicated by the equilibrium constants for the equilibrium reaction involving apatite (see Table 1 in Schrön, 2013), apatite formation may suppress the deposition of schreibersite. This fact may help to explain why schreibersite is rarely observed in chondrites. The apatite found in meteorites is chlorapatite, which suggests that $\mathrm{HCl}$ or metal chlorides are involved in apatite formation.

Schrön (1989b) also describes the formation of cohenite $\mathrm{Fe}_{3} \mathrm{C}$ via a strongly thermodynamically favored back reaction, similar to the situation described for troilite (equilibrium reaction (7)) and schreibersite (equilibrium reaction (8)). Cohenite decomposes on heating into kamacite and graphite. Laboratory measurements made on cohenite of Og Magura and other octahedrites have shown that after heating for $0.35 \mathrm{~h}$ (at $950^{\circ}$ C) $/ 18 \mathrm{~h}\left(\right.$ at $\left.850^{\circ} \mathrm{C}\right) / 75 \mathrm{~h}\left(\right.$ at $\left.750^{\circ} \mathrm{C}\right) / 270 \mathrm{~h}$ (at $650^{\circ} \mathrm{C}$ ), cohenite was no longer detectable (Ringwood \& Seabrook, 1962 and Illner, 1970). Like the occurrence of Widmanstätten patterns (Introduction and Argument 12), the presence of cohenite in Og Magura and other octahedrites is therefore an argument in support of the CFT model and against the idea that these iron meteorites were formed as a result of extremely slow cooling of the melt.

Other minerals whose formation may be influenced by the back reactions of solid-gas equilibrium reactions include daubreelite $\mathrm{FeCr}_{2} \mathrm{~S}_{4}$, oldhamite $\mathrm{CaS}$, and chromite $\mathrm{FeCr}_{2} \mathrm{O}_{4}$ (see Schrön, 1989b).

\section{Argument 12: Formation of nickel-iron meteorites with and without Widmanstätten patterns}

Widmanstätten patterns are composed of the two phases kamacite $\alpha-(\mathrm{Fe}, \mathrm{Ni})$ with a body-centered cubic lattice and taenite $\gamma$-(Fe,Ni) with a face-centered cubic lattice. As already mentioned, the Widmanstätten patterns in octahedrites are irreversibly destroyed at temperatures in excess of $1220 \mathrm{~K}$ (Heide et al., 1995). According to the binary Fe-Ni phase diagram, kamacite and taenite are only stable within the twophase $\alpha+\gamma$ region (Goldstein et al., 2009); only taenite is stable at higher temperatures. However, in the CFT model of the formation of nickel-iron meteorites presented here, neither higher temperatures nor the melting of metal phases is involved. All of the processes described take place at temperatures below the melting point of iron. This opens up entirely new possibilities of how Widmanstätten patterns in meteorites were created. Here we postulate that the Widmanstätten patterns in octahedrites are formed during and in conjunction with the back reaction in equilibrium reaction (2) in processes that are significantly influenced by crystallographic factors such as "a diffusion-controlled nucleation and growth process" (Buchwald, 1975) at temperatures below those at which the Widmanstätten patterns would be irreversibly destroyed and at which the two-phase $\alpha+\gamma$ region is stable. According to the CFT model, the Widmanstätten patterns are generated during the joint deposition of taenite and kamacite from the gas phase (i.e. during the transition from gaseous ionic species to the metallic bonding in the solid metal), with accompanying diffusion processes taking place during cooling. It is thus conceivable that the incorporation of short-lived radionuclides such as ${ }^{60} \mathrm{Fe}$ during the back reaction in equilibrium reaction (2), i.e. while nickel-iron is depositing 


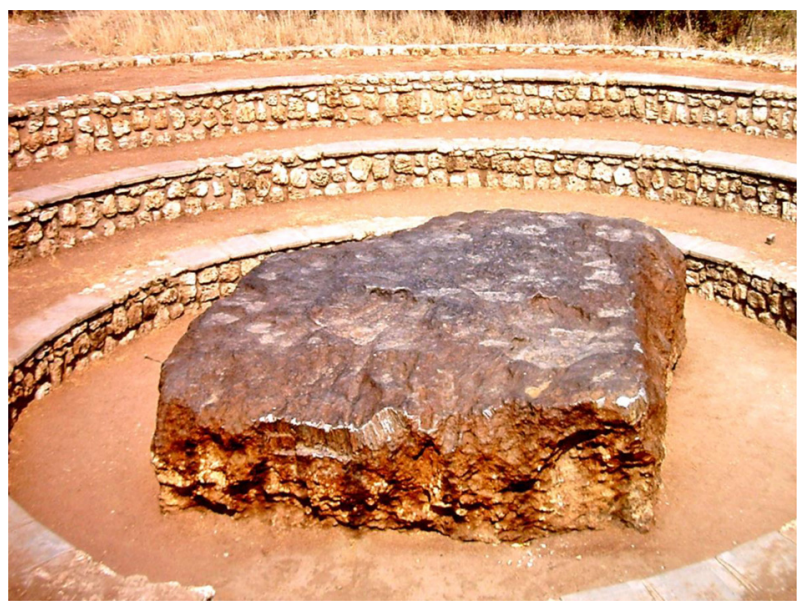

Figure 11. The Hoba ataxite iron meteorite, Grootfontein Namibia. Photograph taken by author, 1998.

from the gas phase, could have favoured or even facilitated the complex processes and interactions that, according to Goldstein et al. (2009), lead to the formation of Widmanstätten patterns. As Amelin et al. (2013) state: "Freshly synthesized short-lived radioactive nuclides are injected into the solar nebula during the first three stages of accretion." If the postulated mechanism is correct, the formation of the Widmanstätten patterns could be regarded as the "masterpiece" of the CFT process. Although the crystallization processes that lead to the formation of Widmanstätten patterns cannot be described in detail at present, it is assumed that crystallization from the gas phase provides better conditions for the formation of Widmanstätten patterns than does the cooling of a melt. It should be possible to test these ideas experimentally.

Like octahedites, hexaedrites can be formed via CFT in the two-phase $\alpha+\gamma$ region by direct deposition of kamacite from the gas phase, provided that nickel is not present in sufficient quantity to facilitate the formation of taenite.

The CFT model is also able to explain the formation of ataxites, though the temperatures involved would be higher than those prevailing during the formation of octahedrites, as these temperatures would need to be high enough so that Widmanstätten patterns would not be stable or would be thermally destroyed. Occasionally, microscopic Widmanstätten patterns have been observed in ataxites (e.g. Hoba and Arltunga). These ataxites were obviously deposited at temperatures that lie between the temperature ranges for the formation of octahedrites and ataxites.

According to the current hypothesis regarding the creation of irons by cooling of the melt, the ataxite Arltunga is the iron meteorite with the highest absolute cooling rate of $500 \mathrm{~K} / \mathrm{Myr}$ (Buchwald, 1975), while the lowest absolute cooling rates are associated with the pallasites $(2-18 \mathrm{~K} / \mathrm{Myr}$ according to Benedix et al., 2014).

Ataxites clearly play a special role in the characterization of the creation of irons. Although they have a somewhat indeterminate structure, at the macroscopic level they lend support to the idea that iron meteorites were formed as fluidites (Figure 11).

\section{Argument 13: Cosmochronology}

Astronomical and cosmochemical timescales use different "zero" reference points. The cosmochemical timescale begins with the formation of CAIs: "[...] CAIs [are] recognized as the oldest macroscopic objects in the Solar System, [...]" (Amelin \& Ireland, 2013, also Kleine, Mezger, Palme, Scherer, \& Münker, 2005; Markowski, Quitte, Halliday, \& Kleine, 2006 in Goldstein et al., 2009) and were "formed 4567 Ma ago" (Goldstein et al., 2009, also Amelin \& Ireland 2013; Amelin et al., 2010). Both absolute ages and ages stated relative to CAIs are common. "Formation of CAIs [...] was followed by the accretion and differentiation of the parent bodies of some magmatic iron meteorites within less than 1 Myr" (Kleine et al., 2009).

Contradictions in ongoing discussions concerning the model age of metal-silicate separation highlight the relevance of CFT to the current debate: "The corrected $\varepsilon^{182} \mathrm{~W}=-3.39 \pm 0.08$ for [H] Negrillos and the measured $\varepsilon^{182} \mathrm{~W}=-3.38 \pm 0.05$ for [Of] Gibeon correspond to $\mathrm{W}$ model ages for core formation of -1.0 $\pm 1.3(2 \sigma)$ and $-0.9 \pm 1.2(2 \sigma)$ Myr after crystallization of type B CAIs" (Kleine et al., 2009) or "Some irons have especially low ${ }^{182} \mathrm{~W} /{ }^{184} \mathrm{~W}$ values, suggesting they may be older than CAIs" (Goldstein et al., 2009) or "[...] the assembly of iron meteorite parent bodies prior to chondrule formation is inconsistent with the standard model for asteroid accretion, in which chondrites represent the precursor material from which asteroids accreted and then differentiated" (Kleine et al., 2009).

There is a special cosmochronological feature that needs to be taken into account when assessing the absolute age of iron meteorites formed by the CFT process. The absolute ages of these irons are mixed as these bodies could have been formed by CFT mobilization in two different equilibrium reactions (equilibrium reactions (1) and (2)). In the case of equilibrium reaction (1), age determination begins with the mobilization process itself; for equilibrium reaction (2), age determination begins prior to mobilization, as the iron was already separate from the silicate phase before mobilization began. Information on the origins of the metal phase in chondrites has been provided by Kong and Ebihara (1996, 1997), Davis and Richter (2014) and Friedrich et al. (2015).

Further insight is likely to be gained if it can be shown that the series ataxites, Of, Off, Om, Ogg, H, Og (see Argument 7) is connected to trends in the absolute ages of these meteorites.

\section{Argument 14: Requirements for and occurrence of CFT in the solar nebula or similar media}

Which requirements have to be met in order for nickel-irons such as octahedrites, hexahedrites and ataxites to be able to form by CFT in a gaseous and dust-containing medium like the solar nebula? Key requirements include the following: 
(1) The presence of the so-called heavier elements (atomic number Z: 3-28)

(2) Maximum temperatures of $1300 \mathrm{~K}$ and above (the maximum could theoretically lie between $1300 \mathrm{~K}$ and the trend temperature of $2000 \mathrm{~K}$ deduced from thermodynamic calculations)

(3) A temperature gradient between the maximum temperature and a temperature of around $600 \mathrm{~K}$

(4) All of the above must be present in an area of space that permits diffusion.

As soon as these conditions have been met, CFT will be effective and nickel-iron bodies will form.

These requirements are clearly met within the asteroid belt, with temperature gradients beginning to appear if not before then certainly with the heating up of the accreting particles.

This study assumes that the conditions for the formation of fluidites were present both in those regions of the protoplanetary disk in which the planets later formed as well as in the main asteroid belt. It is well accepted that accretion in the asteroid belt did not result in the formation of a planet and that this region of the solar system therefore contains numerous small bodies of different types and sizes with properties still unchanged from the time of their formation. These small bodies include the nickel-iron bodies formed by CFT. Some of these nickel-iron bodies, like many of the silicate bodies, have fallen to Earth. This has given us access to unadulterated material from the early phase of the formation of the solar system. Other nickel-iron bodies formed by CFT have accreted with silicate planetesimals to form larger bodies, and in some of these cases, the iron enclosed at the center of such bodies will have melted. According to Goldstein et al. (2009), iron meteorites "may have been derived originally from bodies as large as $1000 \mathrm{~km}$ or more in size." (Note: The older literature suggests that irons were derived from bodies some $50-200 \mathrm{~km}$ in size.) The decay of the radionuclides ${ }^{26} \mathrm{Al}$ und ${ }^{60} \mathrm{Fe}$ are generally considered to be the main heat sources acting during the accretion and melting processes (Sahijpal et al., 2007). The conditions for the formation of stony-iron (igneous) meteorites are therefore met. Without ruling out the magmatic formation of stony irons via homogeneous accretion as described by Goldstein et al. (2009), this study assumes that many stony irons were formed by heterogeneous accretion in the manner described above. According to the ideas presented here, we are now able to explain why the $\mathrm{Ni}-\mathrm{Fe}$ metal in stony irons does not (with the exception of a few pallasites) exhibit Widmanstätten patterns. Any Widmanstätten patterns that were present originally would have been destroyed by melting. The same argument applies to the occurrence of cohenite, which is also found predominantly in octahedrites.

As already stated, this study assumes that the conditions required for fluidite formation were present in the protoplanetary disk during the period of planet formation. The formation of large nickel-iron bodies in the early solar system suggests that the process of accretion that led to the formation of the planets took place at a faster rate, which would have resulted primarily in the deposition of nickel-irons in the planet cores (heterogeneous accretion).

Star formation is a further astronomical scenario in which fluidites formed via CFT may have played a role. The requirements listed above are met within the interstellar cloud once the heavier elements up to iron and nickel can be produced by stellar nucleosynthesis. The size of the iron bodies created in the region around forming stars is not primarily dependent on the concentrations of the elements in the interstellar cloud, but rather on the emerging cyclic processes, that is, size is dependent on time. However, the conditions needed to maintain these cyclic processes by CFT will differ in the two scenarios of star and planet formation.

These ideas give rise to two further arguments.

\section{Argument 15: Distribution of angular momentum in the solar system}

The extraordinary distribution of angular momentum in our solar system in which most of the angular momentum is in the small bodies is a phenomenon that continues to be difficult to explain. One mechanism that has been proposed as a means of facilitating the transfer of angular momentum from the sun to the planets involves the transfer of momentum by coupling between the magnetic field of the protosun and the solar nebula (see Schultz, 1993). It would therefore be of interest to examine whether the postulated formation of numerous moving iron bodies both in the protosun and in the early protoplanetary disk could have had an effect on this mechanism. Potentially, the CFT-driven formation of iron bodies could help to explain the remarkable distribution of mass and angular momentum in the solar system (Schrön, 2013).

\section{Argument 16: Magnetic field in the early universe}

The final argument presented here concerns the largely unexplained problem of magnetogenesis, that is, the origin of cosmological magnetic fields. In light of the ideas postulated in this work, it cannot be ruled out that there is a connection between the iron bodies formed during the early stages of star formation and the observations that seem to suggest a relatively strong and uniform development of cosmological magnetic fields, especially as these magnetic fields arise unexpectedly early and the causes for the creation of magnetic fields in the early universe are still largely unknown (Durrer, 2013; Lesch, 2014).

\section{ANOTHER REMARK}

The arguments presented here can explain more or less all of the findings relating to iron meteorites that have been previously reported and discussed, with the exception of the relatively large difference in the silicon content of irons and stony irons that was observed by Keil (1968). The thermodyn- 
amics of solid-gas equilibrium reactions provides clues that may explain the very low abundances of silicon in iron meteorites. According to the CFT model, silicon reacts preferentially with $\mathrm{HF}$ to form $\mathrm{SiF}_{4}$ which undergoes gas-phase transport from colder to hotter locations. (Schrön, 2013, 1989b). The reaction-conditioned pressure of $\mathrm{SiF}_{4}$ only reaches high values at low temperatures (see Figure 1). The extremely low reaction-conditioned pressures of other silicon halides, such as $\mathrm{SiCl}_{4}$, mean that these compounds do not play a part in CFT in the solar nebula. In the CFT model in which iron meteorites are fluidites, the very low amounts of silicon found in iron meteorites is the result of the absence of silicon and silicon compounds during the back reaction (metal deposition) in equilibrium reaction (2).

It is very probable that at relatively low temperatures in the early solar nebula, transport processes involving $\mathrm{HF}$ will have occurred to a certain extent. Compounds such as $\mathrm{PF}_{5}, \mathrm{POF}_{3}$, $\mathrm{SiF}_{4}$, and other fluoride-containing compounds of lithophile elements, that within the CFT model behave like silicon, are likely to have played a role during that period of the accretion process in which temperatures were lower than those during the metal deposition phase.

Remarks to this effect have already been published elsewhere (Schrön, 1989b, 2013). The following comment from Ahrens (1970 in Mason, 1979) is of interest in this regard: "Perhaps $\mathrm{P}$ was associated with Fe in the early stages of the formation of the common chondrites and later events, whatever they may be, produced minerals in which $\mathrm{P}$ was associated with oxygen." The role of the gas-phase transport of fluorides (and oxyfluorides) in the solar nebula, where the focus is primarily on phosphorous- und silicon-containing minerals, will need to be examined systematically in the future.

\section{RESULTS}

The reaction-conditioned pressures of the halides $\mathrm{p}_{\mathrm{MeCl}}$ that were calculated from chemical thermodynamic data and are shown in Figure 1 have been shown here to be a key factor in understanding certain cosmochemical phenomena. It is the chemical properties of siderophile elements that drive the enrichment of these elements in nickel-iron meteorites, and this thermodynamic driving force finds expression in the reaction-conditioned pressure $\mathrm{p}_{\mathrm{MeCl}}$, which, in addition, provides a means of defining the siderophile character of the elements (Argument 2). The reaction-conditioned pressure $\mathrm{p}_{\mathrm{MeCl}}$ offers a means of explaining the abundance or depletion of elements in the chemical composition of nickel-iron meteorites. The dual-concentration values observed for copper and chromium in iron meteorites can therefore be explained on the basis of the reaction-conditioned pressures $\mathrm{p}_{\mathrm{MeCl}}$ of these two metals (Tables 2 and 4; Figure 9; Arguments 8 and 9).

The excellent correlation between germanium and gallium concentrations in iron meteorites and the extreme differences observed in the germanium abundances are the result of the interplay between the dominance change behavior of the elements $\mathrm{Ge}\left(\mathrm{GeCl}_{2} / \mathrm{GeCl}_{4}\right)$ and $\mathrm{Ga}\left(\mathrm{GaCl}_{3} / \mathrm{Ga}_{2} \mathrm{Cl}_{6}\right)$, the reaction-conditioned pressures $\mathrm{p}_{\mathrm{MeCl}}$ and the high saturation vapor pressures $\mathrm{p}_{\text {Mex }}^{\mathrm{s}}$ for Ge and Ga (Argument 6). The difference in the correlation behavior observed in the element pair Ga-Ge (Figure 4) compared to Ni-Co (Figure 5) is explained by the influence of isomorphism during crystallization from the gas phase (Table 2; Figure 10; Argument 9).

The differences in the trace elements concentrations in C2, C3, H, L, and LL chondrites and in the achondrites compared to their solar elemental abundances (Figure 3 and Table 3) receive a new interpretation in this study, which explains them in terms of the reductions in elemental concentrations that result from meteorite alteration by CFT (Argument 5). In contrast, the chemical composition of the $\mathrm{C} 1$ chondrites is known to largely correspond to the solar abundances of the chemical elements (see Argument 5, Table 3). This would suggest that in $\mathrm{C} 1$ chondrites no alteration by CFT occurred during accretion and that the heating processes (see Arguments 7 and 10) were not active. This appears plausible for the following simple reason: $\mathrm{C} 1$ chondrites do not contain any aluminium and thus did not contain any short-lived radionuclides such as ${ }^{26} \mathrm{Al}$ to act as the heat source. Similar reasoning applies to a number of E4 chondrites (see Table 3).

The presence of the minerals troilite, schreibersite, and cohenite is explainable by their equilibrium constants $K_{p}$, which differ significantly from those of kamacite and taenite. The sequence with which minerals are deposited (crystallize) from the gas phase is determined by differences in thermodynamic stability, with cohenite deposited before schreibersite, schreibersite before troilite, and troilite before kamacite or taenite (Argument 11)-findings that are compatible with the appearance of these minerals in iron meteorites. The crystallization of these minerals from the gas phase results in the formation of iron bodies, which in conjunction with the mobilization processes discussed in this study leads to a de facto separation of metal and silicate. The finding that metalsilicate separation occurred before the planets formed (Argument 10) is the most important planetological result of the CFT model. According to this study, different types of iron bodies deposit (crystallize) from the gas phase at different temperatures, with ataxites formed at somewhat higher temperatures than octahedrites and hexahedrites (Argument 7 and 12).

On the basis of the findings in this study, it can be justifiably claimed that iron meteorites (ataxites, octahedrites and hexahedrites) are cosmic fluidites whose structure and chemical composition has remained unchanged since their formation about $4567 \mathrm{Ma}$ ago.

Extensive mineralogical and geochemical arguments have been presented in this work that demonstrate that iron meteorites can be classified as fluidites and, when taken together, offer a consistent model of how iron meteorites were formed by CFT. The underlying concept is based on the mutual interaction of the following three elements: the thermodynamics of solid-gas equilibrium reactions, the iron-nickel phase diagram, and the 
chemical and physical principles of crystallography. The reaction-conditioned pressures that determine metal deposition (Argument 2) and the equilibrium constants that determine mineral formation (Argument 11) can be derived from the solid-gas equilibrium reactions (1) and (2). The iron-nickel phase diagram describes the occurrence of kamacite and taenite as well as solid-state diffusion processes (Argument 12). The chemical and physical laws governing crystal development play a key role in determining mineral formation, the inclusion of trace elements, the minimum nickel and cobalt contents in iron meteorites (Argument 7) and they also explain the extreme differences in the correlation behavior of the elements in iron meteorites, including the observed element ratios and groupings of element ratios (Argument 7 and 9).

\section{DISCUSSION AND CONCLUSIONS}

The CFT model provides a means of understanding the entire process of iron meteorite the formation, though not all stages of the process can be explained in the same level of detail. The mobilization of gas-phase $\mathrm{MeCl}$ particles by the reaction of $\mathrm{HCl}$ with metal and silicate particles in the solar nebula is a thermodynamically favored process. The efficacy of this process has been demonstrated and is the basis for the observed phenomenon of metal-silicate separation. Somewhat less certain is the claim that CFT is responsible for the observed differences in the abundances of the elements in silicate meteorites compared to their solar elemental abundances. These changes in the elemental abundances assume that over long periods of time cyclic processes occur involving very small hot particles, which subsequently accrete to form chondrites and achondrites. While we do not know the optimum size of the accreting particles with respect to heating rates and alteration, large deviations from the solar elemental abundances only occur for those elements that exhibit high reaction-conditioned pressures $\mathrm{p}_{\mathrm{MeCl}}$-an observation that provides strong support for the ideas being postulated in this study.

The direct deposition or crystallization of the minerals kamacite taenite, troilite, schreibersite and cohenite from the gas phase follows strict thermodynamic and crystallographic rules, and the same applies to the presence of trace elements in these minerals. The distribution of trace elements in iron meteorites is determined by the transport and deposition processes that are an integral part of the CFT model. A number of interesting borderline cases can also be explained by the CFT model. Examples of such are the elemental abundances of copper and chromium, which are not classified as siderophile elements. The transport behavior of copper that is expected on the basis of its reaction-conditioned pressure can be significantly altered by the temperature-dependent reaction dominance switching between $\mathrm{CuCl}$ and $\mathrm{Cu}_{3} \mathrm{Cl}_{3}$ (Figure 1). This explains the dualconcentration values observed for copper (Argument 9). Reaction-dominance switching also plays a role in explaining the elemental abundances observed for germanium and gallium, but, as expected, does not lead to the dual-concentration values seen for copper. High abundances of chromium in iron meteorites are relatively rare as is the occurrence of dual-concentration values. The temperature-dependent transport limit for the reaction-conditioned pressure $\mathrm{p}_{\mathrm{CrCl} 2}$ (Figure 1 ) is obviously only rarely exceeded. The occurrence of Widmanstätten patterns and cohenite in nickel-iron meteorites is interpreted in this study as indicating their underlying fluidite character of these meteorites. Similarly, the formation of hexahedrites, octahedrites and ataxites is better explained by the CFT model than by a magmatic-based concept.

All of the processes mentioned in this study are experimentally testable. In some cases, experimental work should be able to sharpen our understanding of specific factors, such as the role played by isomorphism in determining the distribution of trace elements in ataxites, octahedrites, and hexahedrites.

Numerous arguments suggest that CFT has left its traces not only in the meteorites that originated in the asteroid belt, but possibly also in the solar system and the wider cosmos. The ideas presented here represent only the beginning of a possible reappraisal of numerous cosmochemical phenomena. It will, for example, be necessary to look in detail at the stony irons and to systematically assess the role played by CFT in the formation of the silicate meteorites.

It might seem that the CFT processes described in this study must differ from terrestrial CFT processes, as the phenomena described here are not at first sight observable in the Earth's crust. However, closer inspection shows that siderophile elements have indeed accumulated in the iron ores present in the Earth's crust and that hematite from iron ores exhibits strongly varying germanium concentrations of $400 \mathrm{ppm}$ or more (Schrön web 2013).

\section{ACKNOWLEDGMENTS}

The author thanks Prof. Dr. Esther Schmädicke (Erlangen) and Prof. Dr. Klaus Heide (Jena) for recommending relevant literature, for their significant and helpful suggestions and for critical discussion. He also thanks Bastian Reinwarth (Jena) and Dr. Peter Illner (Karlsruhe) for assistance with preparation of the figures.

\section{REFERENCES}

Amelin, Y., \& Ireland, T. R., (2013). Dating the oldest rocks and minerals in the Solar System. Elements, 9(1), 39-44. http://dx.doi. org/10.2113/gselements.9.1.39.

Amelin, Y., Kaltenbach, A., Iizuka, T., Stirling, C. H., Ireland, T. R., Petaev, M., et al. (2010). U-Pb chronology of the Solar System's oldest solids with variable 238U/235U. Earth and Planetary Science Letters, 300, 343-350. http://dx.doi.org/10.1016/j. epsl.2010.10.015.

Ahrens, L. H. (1970). The composition of stony meteorites-VII. Observations on fractionation between L and H chondrites. Earth and Planetary Science Letters, 9, 345-347. http://dx.doi.org/ 10.1016/0012-821X(70)90133-0.

Anders, E. (1969). Chemische vorgänge während der entstehung des planetensystems. Naturwissenschaften, 56, 180-184. http://dx. doi.org/10.1007/BF01166811. 
Anders, E., \& Grevesse, N. (1989). Abundances of the elements: Meteoritic and solar. Geochimica et Cosmochimica Acta, 53, 197214. http://dx.doi.org/10.1016/0016-7037(89)90286-X.

Barin, I., Knacke, O., \& Kubaschewskij, O. (1973/1977). Thermochemical properties of inorganic substances (Vols. 1 and 2). Heidelberg: Springer-Verlag.

Benedix, B. K., Haack, H., \& McCoy, T. J. (2014). Iron and stony-iron meteorites. In A. M. Davis, H. D. Holland, \& K. K. Turekian (Eds.), Meteorites and cosmochemical processes: Vol. 1. Treatise on geochemistry (2nd ed., pp. 267-285). Elsevier-Pergamon. Oxford: Elsevier.

Binnewies, M., Glaum, R., Schmidt, M., \& Schmidt, P. (2011). Chemische transportreaktionen. Berlin: Walter de Gruyter.

Blander, M., \& Abdel-Gawad, M. (1969). The origin of meteorites and the constrained equilibrium condensation theory. Geochimica et Cosmochimica Acta, 33, 701-716. http://dx.doi.org/10.1016/ 0016-7037(69)90116-1.

Bottke, W. F., Nesvorný, D., Grimm, R. E., Morbidelli, A., \& O’Brien, D. P. (2006). Iron meteorites as remnants of planetesimals formed in the terrestrial planet region. Nature, 439, 821-824. http://dx.doi. org/10.1038/nature04536.

Breithaupt, A. (1849). Die paragenesis der mineralien. Freiberg, Sachsen: Verlag von J. G. Engelhardt.

Buchwald, V. F. (1975). Handbook of iron meteorites. Arizona State University: University of California Press.

Bunsen, R. W. (1852). VI. Notizen. 1.Vulkanische Exhalationen. J. prakt. Chem., 56, 53-55.

Chabot, N. L., \& Haack, H. (2006). Evolution of asteroidal cores. In D. S. Lauretta \& H. Y. McSween (Eds.), Meteorites and the early Solar System II (pp. 747-771). Tucson: University of Arizona Press.

Corrigan, C. M., \& Libourel, G. (2014). Asteroids. Elements, 10(1), 11-50. http://dx.doi.org/10.2113/gselements.10.1.11.

Daubree, A. (1880). Synthetische studien zur experimental-geologie. Braunschweig, p. 596.

Davis, A. M., \& Richter, F. M. (2014). Condensation and evaporation of Solar System materials. In A. M. Davis, H. D. Holland, \& K. K.Turekian (Eds.), Meteorites and cosmochemical processes: Vol. 1. Treatise on geochemistry (2nd ed., pp. 335-360). Elsevier-Pergamon. Oxford: Elsevier.

Durrer, R. (2013, December 9). Kosmologische Magnetfelder. Lecture given at the Physikalisches Kolloquium, Friedrich-SchillerUniversität Jena.

Feng, L., El Goresy, A., Zhang, J., Hao, J., Boyet, M., \& Lin, Y. (2012). Excess $36 S$ in lawrencite and nitrogen isotopic compositions of sinoite from Almahata Sitta MS-17 EL3 chondrite fragment. 43rd Lunar and Planetary Science Conference 2012. Retrieved May 2014, from http://www.lpi.usra.edu/meetings/lpsc2012/ pdf/1766.pdf.

Friedrich, J. M., Weisberg, M. K., Ebel, D. S., Biltz, A. E., Corbett, B. M., Iotzov, I. V., et al. (2015). Chondrule size and related physical properties: A compilation and evaluation of current data across all meteorite groups. Chemie der Erde, 75(4), 419-443. http://dx. doi.org/10.1016/j.chemer.2014.08.003.

Fuchs, L. H., \& Olsen, E. (1973). Composition of metal in type III carbonaceous chondrites and its relevance to the source-assignment of lunar metal. Earth and Planetary Science Letters, 18(3), 379-384. http://dx.doi.org/10.1016/0012-821X(73)90093-9.

Gluschko, V. P., \& Gurvic, L. V. (1978/1982). Thermodynamische Eigenschaften spezieller Stoffe (Vols. 1-4). Moskau: Izdatel'stvo Nauk. (in Russian).

Gluschko, V. R. (1971/1981). Die thermodynamischen Konstanten der Stoffe (Vols. 4-7 und 9-10). Moskau: Izdatel'stvo Nauk. (in Russian).

Goldstein, J. I., Scott, E. R. T., \& Chabot, N. L. (2009). Iron meteorites: Crystallization, thermal history, parent bodies, and origin. Chemie der Erde, 69, 293-325. http://dx.doi.org/10.1016/j.chemer.2009.01.002.
Goles, G. G., Greenland, L. P., \& Jerome, D. Y. (1967). Abundances of chlorine, bromine and iodine in meteorites. Geochimica et Cosmochimica Acta, 31, 1771-1787. http://dx.doi.org/10.1016/ 0016-7037(67)90121-4.

Grossman, J. (2016). Meteoritical Bulletin Database. Retrieved from http://www.lpi.usra.edu/meteor/metbull.php.

Grossman, L. (1972). Condensation in the primitive Solar Nebula. Geochimica et Cosmochimica Acta, 36, 597-619. http://dx.doi.org/ 10.1016/0016-7037(72)90078-6.

Grossman, L., \& Larimer, J. W. (1974). Early chemical history of the Solar System. Reviews of Geophysics and Space Physics, 12(1), 71-101. http://dx.doi.org/10.1029/RG012i001p00071.

Heide, F. (1957). Kleine Meteoritenkunde. Göttingen: Springer-Verlag.

Heide, F., \& Wlotzka, F. (1995). Meteorites messengers from space. New York: Springer-Verlag.

Illner, N. (1970). Beitrag zur Kenntnis des meteoritischen Cohenits (Fe,Ni,Co)3C. Chemie der Erde, 28(3/4), 331-372.

JANAF. (1971). Thermochemical tables, N SRDS-NBS 37. Clearing house.

Keil, K. (1968). Mineralogical and chemical relationships among enstatite chondrites. Journal Geophysical Research, 73(22), 69456976. http://dx.doi.org/10.1029/JB073i022p06945.

Kleine, T., Mezger, K., Palme, H., Scherer, E., \& Münker, C. (2005). Early core formation in asteroids and late accretion of chondrite parent bodies: Evidence from $182 \mathrm{Hf}-182 \mathrm{~W}$ in CAIs, metal-rich chondrites, and iron meteorites. Geochimica et Cosmochimica Acta, 69, 5805-5818. http://dx.doi.org/10.1016/j.gca.2005.07.012.

Kleine, T., \& Rudge, J. F. (2011). Chronometry of meteorites and the formation of the Earth and Moon. Elements, 7(1), 41-46. http:// dx.doi.org/10.2113/gselements.7.1.41.

Kleine, T., Touboul, M.,Bourdon,B., Nimmo, F.,Mezger, K., Palme,H., et al. (2009). Hf-W chronology of the accretion and early evolution of asteroids and terrestrial planets. Geochimica et Cosmochimica Acta, 73(17),5150-5188. http://dx.doi.org/10.1016/j.gca.2008.11.047.

Kong, P., \& Ebihara, M. (1996). Metal phases of L chondrites: Their formation and evolution in the nebula and in the parent body. Geochimica et Cosmochimica Acta, 60(14), 2667-2680. http://dx. doi.org/10.1016/0016-7037(96)00111-1.

Kong, P., \& Ebihara, M. (1997). The origin and nebular history of the metal phase of ordinary chondrites. Geochimica et Cosmochimica Acta, 61(11), 2317-2329. http://dx.doi.org/10.1016/S0016-7037 (97)00087-2.

Krabbes, G., \& Oppermann, H. (1977). Die thermodynamik der verdampfung der kupfer-halogenide. Zeitschrift für anorganische und allgemeine Chemie, 435, 33-44.

Krot, A. N., Keil, K., Scott, E. R. D., Goodrich, C. A., \& Weisberg, M. K. (2008). Classification of meteorites. In A. M. Davis (Ed.), Meteorites, comets and planets, treatise on geochemistry update I (pp. 1-52). Amsterdam: Elsevier.

Larimer, J. W. (1967). Chemical fractionations in meteorites -I. Condensation of the elements. Geochimica et Cosmochimica Acta, 31, 1215-1238. http://dx.doi.org/10.1016/S0016-7037(67)80013-9.

Lesch, H. (2014, January 6). Entstehung und Entwicklung von Magnetfeldern in Galaxien und Galaxienhaufen. Lecture given at the Physikalisches Kolloquium, Friedrich-Schiller-Universität Jena.

Lin, Y., El Goresy, A., Boyet, M., Feng, L., Zhang, J., \& Hao, J. (2011). Earliest solid condensates consisting of the assemblage oldhamite, sinoite, graphite and excess 365 in lawrencite from Almahata Sitta MS-17 el3 chondrite fragment. Formation of the first solids in the solar system. 9040.pdf. Retrieved May 2014, from http://www.lpi. usra.edu/meetings/solids2011/pdf/9040.pdf

Lovering, J. F., Nichiporuk, W., Chodos, A., \& Brown, H. (1957). The distribution of gallium, germanium, cobalt, chromium and copper in iron and stony-iron meteorites in relation to nickel content and structure. Geochimica et Cosmochimica Acta, 11, 263-278. http:// dx.doi.org/10.1016/0016-7037(57)90099-6. 
Markowski, A., Quitte, G., Halliday, A. N., \& Kleine, T. (2006). Tungsten isotopic compositions of iron meteorites: Chronological constraints vs. cosmogenic effects. Earth and Planetary Science Letters, 242,1-15. http://dx.doi.org/10.1016/j.epsl.2005.11.048.

Mason, B. (1971). Handbook of elemental abundances in meteorites. New York: Gordon and Breach Science, p. 555.

Mason, B. (1979). Meteorites. Data of geochemistry, Chapter B. Cosmochemistry, Geology survey professional paper; 440-B-1. Washington: United States Government Printing Office.

McCoy, T. J., Mittlefehldt, D., \& Wilson, L. (2006). Asteroid differentiation. In D. S. Lauretta \& H. Y. McSween (Eds.), Meteorites and the early Solar System II (pp. 733-745). Tucson: University of Arizona Press.

Naumov, G. B., Ryzenko, B. N., \& Chodakovski, I. L. (1971). Nachschlagewerk für thermodynamische Daten. Moskau: Atomizdat, p. 239. (in Russian).

Neufeld, D. A., Zmuidzinas, J., Schilke, P., \& Phillips, T. G. (1997). Discovery of interstellar hydrogen fluoride. Astrophysical Journal, 488(2), L141-L144. http://dx.doi.org/10.1086/310942.

Oppermann, H., Schmidt, D., \& Kleinert, P. (1983). Zur Reaktion des Germaniums mit Germanium-tetrachlorid und zur Existenz der Oxidchloride $\mathrm{GeOCl}$ und $\mathrm{GeOCl6}$ im Gleichgewicht. Zeitschrift Fur Anorganische Und Allgemeine Chemie, 506, 7-12.

Ringwood, A. E., \& Seabrook, M. (1962). Cohenite as a pressure indicator in iron meteorites II. Geochimica et Cosmochimica Acta, 26, 507. http://dx.doi.org/10.1016/0016-7037(62)90097-2.

Sahijpal, S., Soni, P., \& Gagan, G. (2007). Numerical simulations of the differentiation of accreting planetisimals with $26 \mathrm{Al}$ and $60 \mathrm{Fe}$ as the heat sources. Meteoritics and Planetary Science, 42(9), 15291548. http://dx.doi.org/10.1111/j.1945-5100.2007.tb00589.x.

Schäfer, H. (1962). Chemische transportreaktionen. Weinheim: Verlag Chemie.

Schäfer, H., Jacob, H., \& Etzel, K. (1956). Chemische transportreaktionen. I Über den Transport des Bodenkörpers im Temperaturgefälle mit Hilfe heterogener Gleichgewichte. Zeitschrift Fur Anorganische Und Allgemeine Chemie, 286, 27-41.

Schrön, W. (1989a). Solid-gas-equilibria in geo-und cosmochemistry -I Geochemistry. European Journal Mineralogy, 1, 739-763. http://dx.doi.org/10.1127/ejm/1/6/0739.

Schrön, W. (1989b). Solid-gas-equilibria in geo-und cosmochemistry -II Cosmochemistry. European Journal Mineralogy, 1, 765-782. http://dx.doi.org/10.1127/ejm/1/6/0765.

Schrön, W. (1990). Fest-Gas-Gleichgewichte in der Kosmo- und Geochemie. Gerlands Beiträge zur Geophysik, 99, 135-155.

Schrön, W. (1994). Genesis of tin-tungsten quartz veins and greisen zones $-A$ thermodynamic trend analysis. Monograph series on mineral deposits 31. Berlin: Gebrüder Borntraeger, pp. 47-60.

Schrön web. (2013). Geochemie Germanium in Chemischer Fluida Transport. www.fluidite.de

Schrön, W. (2013). Chemical fluid transport (CFT), a window into Earth and its development. Chemie der Erde, 73, 421-428. http:// dx.doi.org/10.1016/j.chemer.2013.09.004.

Schrön, W., Oppermann, H., Rösler, H. J., \& Brand, P. (1988). Fest-GasReaktionen als Ursache geo-und kosmogeochemischer Mobilisierungs-und Anreicherungsprozesse. Chemie der Erde, 48, 35-54.

Schultz, L. (1993). Planetologie, Eine Einführung. Basel: Birkhäuser Verlag.

Scott, E. R. D. (1972). Chemical fractionation in iron meteorites and its interpretation. Geochimica Cosmochimica Acta, 36, 1205-1236. http://dx.doi.org/10.1016/0016-7037(72)90046-4.
Saxena, S. K. (1981). Planetary phase equilibria: Application to formation of Earth, Venus and Mercury. Geochimica Cosmochimica Acta, 45, 813-820. http://dx.doi.org/10.1016/0016-7037(81)90110-1.

Suess, H. E. (1965). Chemical evidence bearing on the origin of the solar system. Annual Review of Astronomy and Astrophysics, 3, 217-234. http://dx.doi.org/10.1146/annurev.aa.03.090165.001245.

Tachibana, S., \& Tsuchiyama, A. (1998). Incongruent evaporation of troilite (FeS) in the primordial solar nebula: An experimental study. Geochimica Cosmochimica Acta, 62(11), 2005-2022. http:// dx.doi.org/10.1016/S0016-7037(98)00122-7.

Urey, H. C. (1952). The planets. Their origin and development. New Haven, CT: Yale University Press.

Wai, C. M., \& Wasson, J. T. (1977). Nebular condensation of moderately volatile elements and their abundances in ordinary chondrites. Earth and Planetary Science Letters, 36, 1-13. http://dx.doi.org/ 10.1016/0012-821X(77)90182-0.

Wasson, J. T. (1974). Meteorites, classification and properties. Berlin: Springer-Verlag.

Wedepohl, K. H. (1970/1972). Handbook of geochemistry (Vol. II/3). Berlin: Springer-Verlag.

Weisberg, M. K., McCoy, T. J., \& Krot, A. N. (2006). Systematics and evaluation of meteorite classification. In D.S. Lauretta, H. Y. McSween Jr., eds, Meteorites and the early Solar System II (pp. 19-52). Tucson, AZ: University of Arizona Press.

Wolf, E., Oppermann, H., Krabbes, G., Reichelt, W. (1978). Current topics in material science. 1. North Holland Publ. Comp. Amsterdam, New York: Oxford, $697 \mathrm{p}$.

Yang, J., Goldstein, J. I., \& Scott, E. R. D. (2007). Iron meteorite evidence for early formation and catastrophic disruption of protoplanets. Nature, 446, 888-891. http://dx.doi.org/10.1038/nature05735.

\section{COMPETING INTERESTS}

The author declares no competing interests.

\section{PUBLISHING NOTES}

(C) 2016 Schrön. This work has been published open access under Creative Commons Attribution License CC BY 4.0, which permits unrestricted use, distribution, and reproduction in any medium, provided the original work is properly cited. Conditions, terms of use and publishing policy can be found at www. scienceopen.com.

Please note that this article may not have been peer reviewed yet and is under continuous post-publication peer review. For the current reviewing status please click here or scan the QR code on the right.

$\underset{\text { research+publishing network }}{\text { Sciem }}$

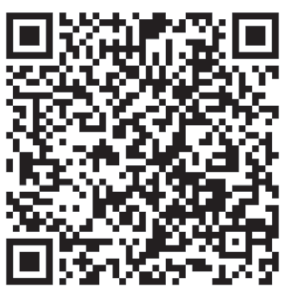

